University of Wollongong

Research Online

Faculty of Engineering and Information

Faculty of Engineering and Information

Sciences - Papers: Part A

Sciences

$1-1-2016$

Special rolling techniques for improvement of mechanical properties of ultrafine-grained metal sheets: a review

Hai Liang Yu

University of Wollongong, hailiang@uow.edu.au

Cheng Lu

University of Wollongong, chenglu@uow.edu.au

Anh Kiet Tieu

University of Wollongong, ktieu@uow.edu.au

Hui Jun Li

University of Wollongong, huijun@uow.edu.au

Ajit R. Godbole

University of Wollongong, agodbole@uow.edu.au

See next page for additional authors

Follow this and additional works at: https://ro.uow.edu.au/eispapers

Part of the Engineering Commons, and the Science and Technology Studies Commons

Research Online is the open access institutional repository for the University of Wollongong. For further information contact the UOW Library: research-pubs@uow.edu.au 


\title{
Special rolling techniques for improvement of mechanical properties of ultrafine- grained metal sheets: a review
}

\author{
Abstract \\ Interest in ultrafine-grained (UFG) materials has grown rapidly in past 20 years. This review focuses on the \\ application of special rolling techniques for improvement of the mechanical properties of UFG metal \\ sheets. These techniques include asymmetric rolling, cryorolling, asymmetric cryorolling, cross- \\ accumulative roll bonding, and skin-pass rolling. The techniques also include a combination of processes \\ such as equal channel angular press and subsequent rolling, combined high-pressure torsion and \\ subsequent rolling, as well as combined accumulative roll bonding and subsequent asymmetric rolling. \\ We also discuss the main mechanisms leading to improvement in the ductility of UFG materials related to \\ the special rolling techniques.
}

\section{Keywords}

sheets, metal, grained, ultrafine, review, properties, special, mechanical, improvement, techniques, rolling

\section{Disciplines}

Engineering | Science and Technology Studies

\section{Publication Details}

Yu, H. Liang., Lu, C., Tieu, A. Kiet., Li, H. Jun., Godbole, A. \& Zhang, S. Hong. (2016). Special rolling techniques for improvement of mechanical properties of ultrafine-grained metal sheets: a review. Advanced Engineering Materials, 18 (5), 754-769.

\section{Authors}

Hai Liang Yu, Cheng Lu, Anh Kiet Tieu, Hui Jun Li, Ajit R. Godbole, and Shi-Hong Zhang 


\title{
Special rolling techniques for improvement of mechanical properties of ultrafine-grained metal sheets: a review**
}

By Hailiang $Y U^{*}$, Cheng LU, A. Kiet TIEU, Huijun LI*, Ajit GODBOLE, and Shihong ZHANG

\begin{abstract}
Interest in ultrafine-grained materials has grown rapidly in past twenty years. This review focuses on the application of special rolling techniques for improvement of the mechanical properties of ultrafine-grained (UFG) metal sheets. These techniques include asymmetric rolling, cryorolling, asymmetric cryorolling, cross-accumulative roll bonding and skin-pass rolling. The techniques also include a combination of processes such as equal channel angular press and subsequent rolling, combined high pressure torsion and subsequent rolling, as well as combined accumulative roll bonding and subsequent asymmetric rolling. We also discuss the main mechanisms leading to improvement in the ductility of UFG materials related to the special rolling techniques.
\end{abstract}

Keywords: asymmetric rolling; cryorolling; skin-pass rolling; accumulative roll bonding; severe plastic deformation

\section{Introduction}

In recent decades, researchers have paid considerable attention to developing bulk ultrafine-grained (UFG) or nano-grained (NG) metals, due to their many desirable properties. ${ }^{[1-4]} \mathrm{A}$ number of articles have reviewed the application of severe plastic deformation (SPD) techniques to UFG/NG metals. ${ }^{[5-13]}$ In these reviews, researchers have mainly focused on only a limited number of SPD techniques: the equal channel angular press (ECAP), ${ }^{[7,9]}$ high pressure torsion (HPT), ${ }^{[8]}$ and accumulative roll

[*] Dr. H.L. YU, A/Prof. C. LU, Prof. A. K. TIEU, Prof. H.J. LI, Dr. A. GODBOLE,

School of Mechanical, Materials \& Mechatronic Engineering, University of Wollongong, NSW 2500, Australia.

E-mail: YU H. L., hailiang@uow.edu.au; yuhailiang1980@tom.com

LIH.J., huijun@uow.edu.au

Prof. S.H. ZHANG

Institute of Metal Research, Chinese Academy of Science, Shenyang 110016, China.

[**] Funding from the Vice-Chancellor's Fellowship Grant and URC small grant at the University of Wollongong, and the Open Research Fund of Key Laboratory of High Performance Complex Manufacturing, Central South University. 
bonding (ARB). ${ }^{[13]}$ However, to date, there is not a review focusing on the application of other advanced rolling techniques leading to improvement in the mechanical performance of the products, even though the vast majority of all metal products in use are manufactured using metal rolling techniques. ${ }^{[14]}$

Rolling techniques have a long history dating back more than 100 years. Generally, the researchers have focused on product profile, ${ }^{[15-19]}$ product defects, ${ }^{[20-26]}$ product microstructure, ${ }^{[27-30]}$ wear and lubrication of roll mill, ${ }^{[31-34]}$ etc. With the rapid development of UFG/NG metals, severe plastic deformation techniques have become increasingly important in rolling. Apart from the accumulative roll bonding technique, ${ }^{[35-38]}$ some other rolling methods were also considered as SPD techniques. Because there have already been some reviews of the progress in the ARB technique, ${ }^{[13]}$ in this paper we have focused on the progress of other rolling techniques such as asymmetric rolling (AR), cryorolling (CR), asymmetric cryorolling (ACR), improved ARB technique, and the combination of other SPD and rolling techniques in recent years.

\section{Fabrication Methods}

\subsection{Asymmetric Rolling (AR)}

In ECAP and HPT, grain refinement is brought about mainly by the shear strain in the workpiece during the deformation. On the other hand, in AR, the workpiece is subjected to severe shear strain combined with a normal strain. Fig. 1 illustrates AR technique. The strain in the workpiece can be predicted by Eq. (1): ${ }^{[39]}$

$$
\varepsilon=\frac{2}{\sqrt{3}}\left\{1+\left[\frac{(1-r)^{2}}{r(2-r)} \tan \theta\right]^{2}\right\}^{1 / 2} \ln \frac{1}{1-r}
$$

where

$$
r=1-\left(t_{1} / t_{0}\right)
$$

Here $t_{0}$ and $t_{1}$ are the thickness of the sheet before and after AR, and $\theta$ is the apparent shear angle at a given position of the element w.r.t. the perpendicular to the surface of the sheet before rolling. Compared to symmetric rolling (SR), AR can develop greater plastic deformation since it develops an additional shear strain for a given reduction in 
thickness. The shear deformation is more severe in the lower layers, where the work roll speed, roll diameter, or friction coefficient is greater than those in the upper layers. ${ }^{[40]}$ In addition, due to the shear deformation, AR is better suited to producing thin foils ${ }^{[41,42]}$ and improving the formability of foils. $\mathrm{A} \mathrm{Cu}$ foil with an extreme elongation of up to $43684 \%$ by AR was reported recently. ${ }^{[42]}$ In AR-processed products, plastic strain ratio values and consequently formability can be improved by some shear texture components. For face centered cubic materials, the AR technique avoids the uniqueness issue related to the choice of the set of active slip systems by applying a Schmid Law. ${ }^{[43]}$ The strain histories and distributions in the sheets and the texture evolution during AR were measured and calculated by Kim and Lee ${ }^{[44]}$ in order to understand the evolution of normal direction (ND)//<111 $>$ in $\mathrm{Al}$ sheets. They found that the ideal shear deformation texture can be obtained by reversing the AR direction intermittently.
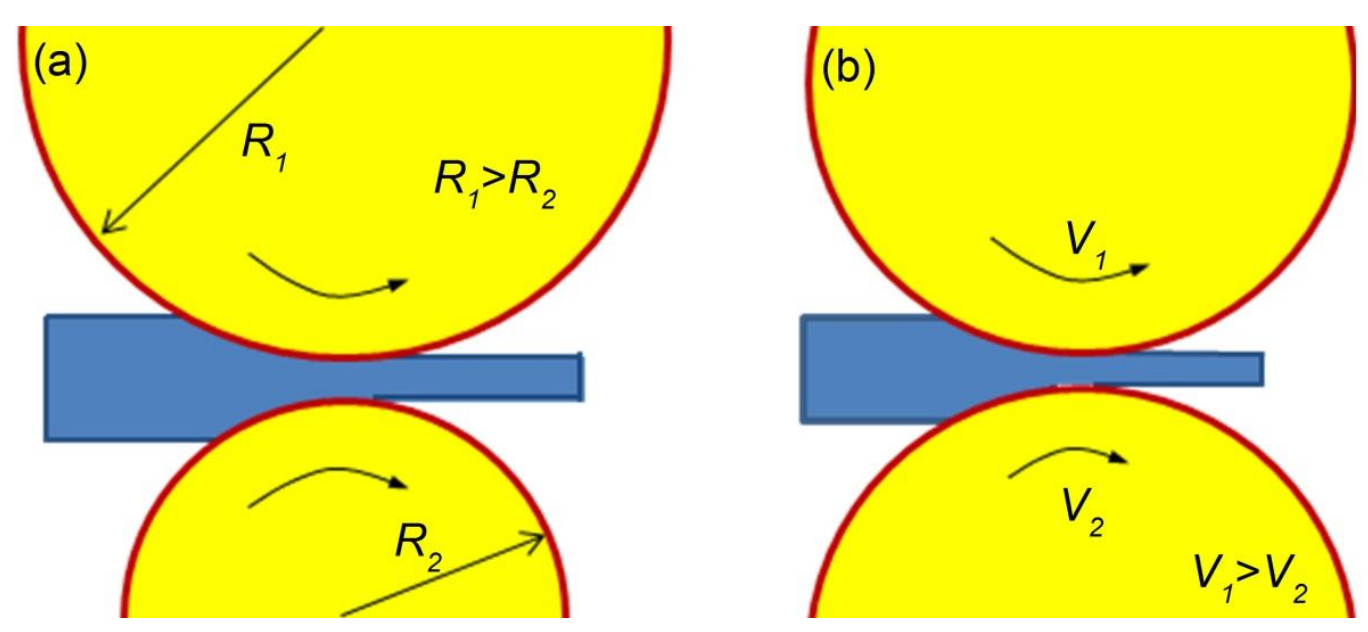

Fig. 1. Illustration of asymmetric rolling. (a) different work roll diameters; (b) different work roll speeds.

Under the right conditions, AR can impose intense shear deformation across the sheet thickness, leading to not only the occurrence of shear texture, but also the grain refinement. AR is thus considered as an SPD technique. Compared to SR, AR results in additional shear strain and thus grain refinement through the transformation of sub-boundaries into high-angle boundaries. Both SR and AR techniques were 
employed to Al 6016 alloy by Sidor et al. ${ }^{[45]}$ They found that in AR-processed sheets, the shear deformation texture was not retained in recrystallization processing. Instead, a weak non-conventional texture was found to develop with a Goss component rotated through $90^{\circ}$, in addition to displaced shear texture components. A non-conventional asymmetric $r$-value profile was determined by the monoclinic sample symmetry. The improvement of normal anisotropy in AR-processed sheets $(\bar{r}>0.9)$ results in a greater limiting drawing ratio of $\sim 2.17$, which is beneficial to the sheet formability. The mechanical properties and microstructure of both AR- and SR-processed Al were studied by Cui ${ }^{[39]}$ and Jiang et al ${ }^{[46]}$ respectively. The yield strength was substantially increased by an AR process as shown in Fig. 2. ${ }^{[46]}$ Nearly equiaxed UFGs with mean size $<1 \mu \mathrm{m}$ were achieved through AR when the rolling reduction ratio reached $90 \%$. The microstructure was homogeneous and high-angle boundaries were predominant. On the other hand, in SR-processed sheet, the coarse fibrous structure was predominant.

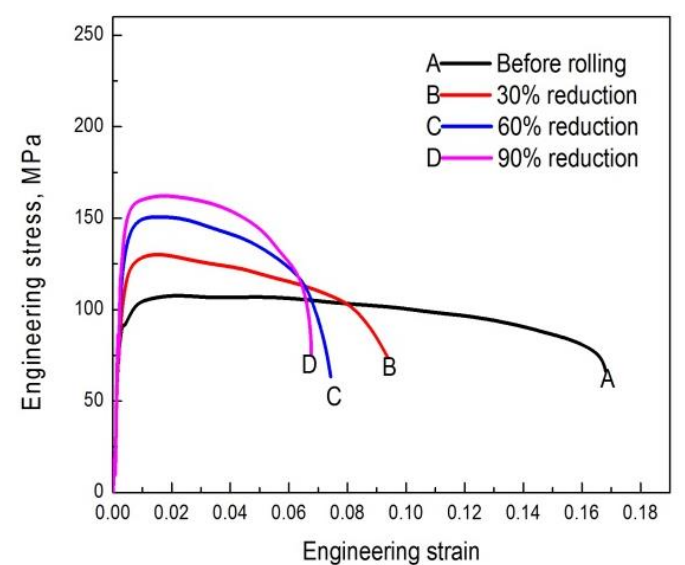

(a)

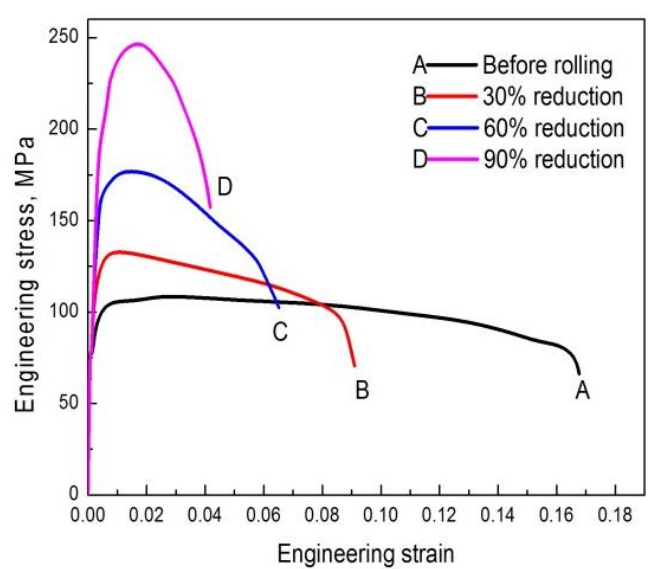

(b)

Fig. 2. Engineering stress vs engineering strain curves of Al by (a) symmetric rolling and (b) asymmetric rolling. ${ }^{[46]}$

Compared to an $\mathrm{Al}$ alloy sheet, the $\mathrm{Mg}$ sheet is difficult to process using SR because it has less deformation system. In this respect, the AR technique has more advantages. The persistence characteristics of ideal orientations in AR-processed commercially pure $(\mathrm{CP}) \mathrm{Mg}$ samples are: ${ }^{[47]}$ (i) their location on boundaries of 
positive/negative divergence zones and (ii) their velocity field does not display a mirror symmetry that provides the feasibility of employing different 'routes' to dominate the ultimate texture. The AR technique induces a shear component that shifts the texture fiber by $\sim 5^{\circ}-10^{\circ}$ compared to SR. ${ }^{[48]}$ If a small shear component is induced during AR, it enhances the ductility. A smaller grain size and greater dislocation density accompanied by high fraction of low-angle grain boundary improves the strength. Compared to SR, the AR technique effectively weakens the orientation of the basal plane in the rolling plane and enhances the press formability. Watanabe et al ${ }^{[49,50]}$ studied the mechanical properties of AR-processed and SR-processed AZ31 sheet at different rolling temperatures. They found that the strength was not affected by rolling temperature. However, the elongation to failure enhanced from $13.6 \%$ to $18.5 \%$ when the rolling temperature was reduced from 573 $\mathrm{K}$ to $473 \mathrm{~K}$. Ma et al ${ }^{[51]}$ also studied AZ31 sheets processed using AR. They found that a large shear stress can be introduced throughout the thickness of sheet. This could promote dynamic recrystallization during $\mathrm{AR}$, resulting in a homogeneous microstructure with much finer grains and weakened basal texture. AR-processed sheets exhibit superior mechanical properties: a higher yield strength $\sim 180 \mathrm{MPa}$, and ultimate tensile strength $\sim 270 \mathrm{MPa}$. This compares favorably with yield strength of $\sim 155 \mathrm{MPa}$ and an ultimate tensile strength of $\sim 230 \mathrm{MPa}$ in SR-processed sheets. Simultaneously, the elongation to failure of AR-processed sheets is $19 \%$ is higher than that of the sheet by SR (15\%), as shown in Fig. 3 . 


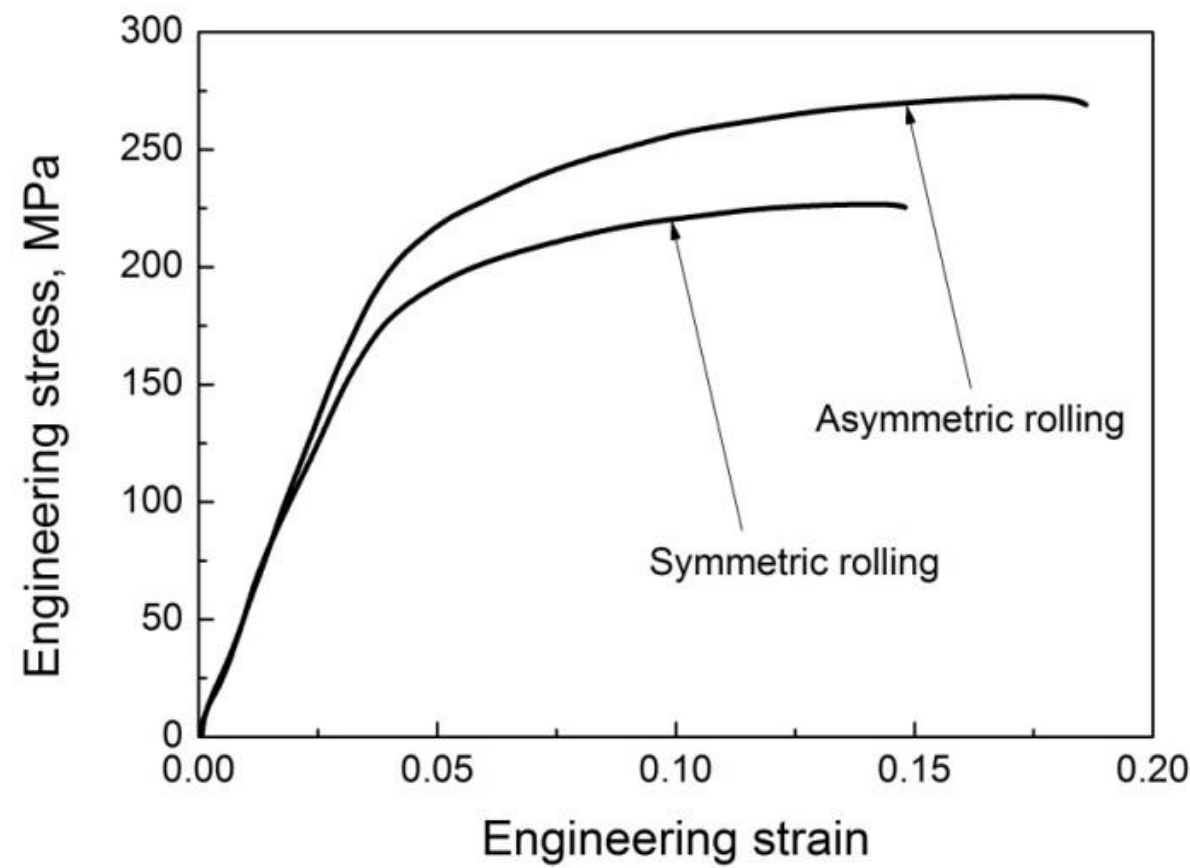

Fig. 3. Engineering stress vs engineering strain curves of AZ31 sheets fabricated by asymmetric rolling and symmetric rolling with a $25 \%$ reduction. ${ }^{[51]}$

The AR technique has also been applied to steel, Ti and silver alloys. The best combination of strength and yield ratio for low-carbon steel can be achieved through a low-level AR deformation and a high cooling rate, which causes a part of the austenite to transform into martensite with fine ferrite grains $(\sim 2 \mu \mathrm{m}) .{ }^{[52]}$ The AR technique can result in a gradient of ultrafine (ferrite +martensite) duplex structure in low carbon steel, ${ }^{[53]}$ in which two specific fiber textures $<100>/ / \mathrm{RD}$ and $<111>/ / \mathrm{ND}$ are developed through the thickness when a shear strain is imposed. However, the thermal stability of AR-processed steel sheet may be lower than that of SR-processed steel, due to a higher level of stored energy in the as-deformed microstructure. ${ }^{[54]} \mathrm{NG} \mathrm{CP-Ti}$ with mean grain size of $80 \mathrm{~nm}$ was fabricated by a combination of AR and SR by Li et al. ${ }^{[55]}$ Annealing of NG Ti at $473 \mathrm{~K}$ for 20 min results in an obvious improvement in the strength, microhardness, and ductility as compared to the as-processed state. Angella et al ${ }^{[56]}$ compared the microstructure evolution and mechanical properties of silver produced by ECAP and by AR (roll speed ratio 1.4). In ECAP-processed silver the strength increased at former passes and then displayed a plateau for the whole range of applied strain. In AR-processed samples, the strength nearly constantly 
increased even at larger strains. The TEM-observed microstructure confirms that while the ECAP-processed sliver shows equiaxed UFG grains with sharp boundaries and grain interiors with fairly low dislocation density, the AR-processed samples displayed a magnificent presence of dislocations both at the grain boundaries and inside the grains, as shown in Fig. 4.
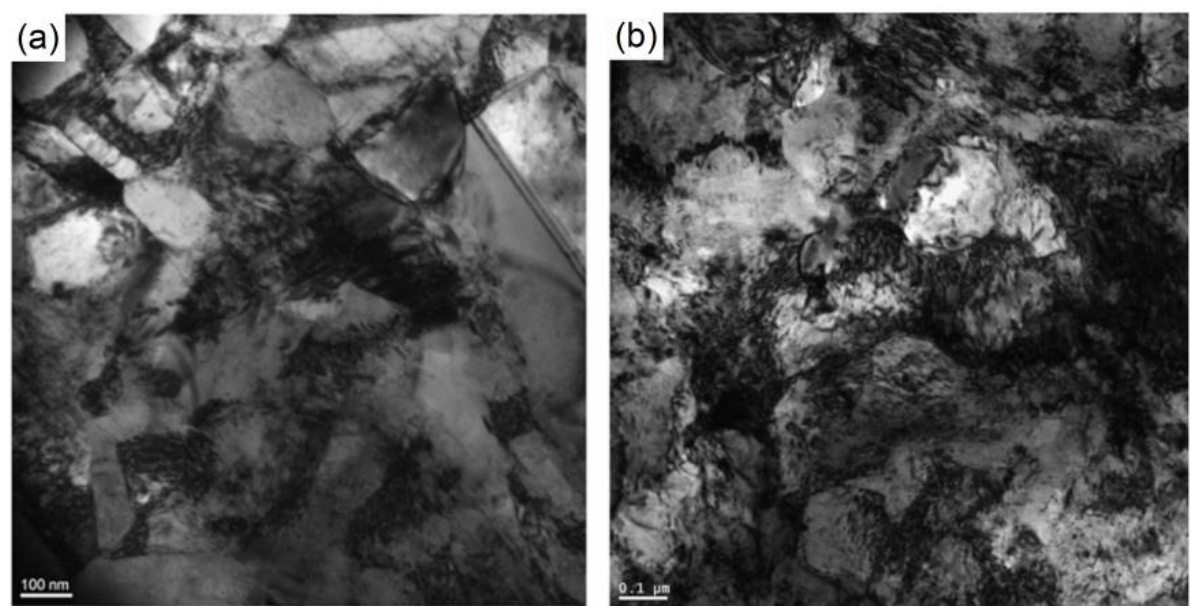

Fig. 4. TEM images of silver samples for (a) ECAP with equivalent strain of 4.22 and (b) asymmetric rolling with equivalent strain of 6.12. ${ }^{[56]}$

\subsection{Cryorolling (CR)}

Deformation at cryogenic temperatures has emerged as a potential method to fabricate UFG/NG materials with a high dislocation density for enhanced mechanical properties. CR is a rolling technique which liquid nitrogen or other coolant is used to cool down the samples, as shown in Fig. 5. The dynamic recovery is suppressed at low temperature, thereby improving the grain-refinement. The CR technique paves the way for industrial application of the advanced production line of cold surface hardening. ${ }^{[57]}$ Mechanically induced microstructure transformation hardens the machine tools and thus carries the potential of economic savings and high flexibility of production. The effectiveness of the $\mathrm{CR}$ on strengthening is remarkably influenced by stacking fault energy (SFE). Subramanya Sarma et al ${ }^{[58]}$ believed that low SFE metals deformed by twinning and high SFE metals deformed by dislocation slip 
during CR. Intermediate SFE metals deformed by twinning during CR but dislocation slip during room temperature rolling, which makes CR the most effective over room temperature rolling in improving the strength.

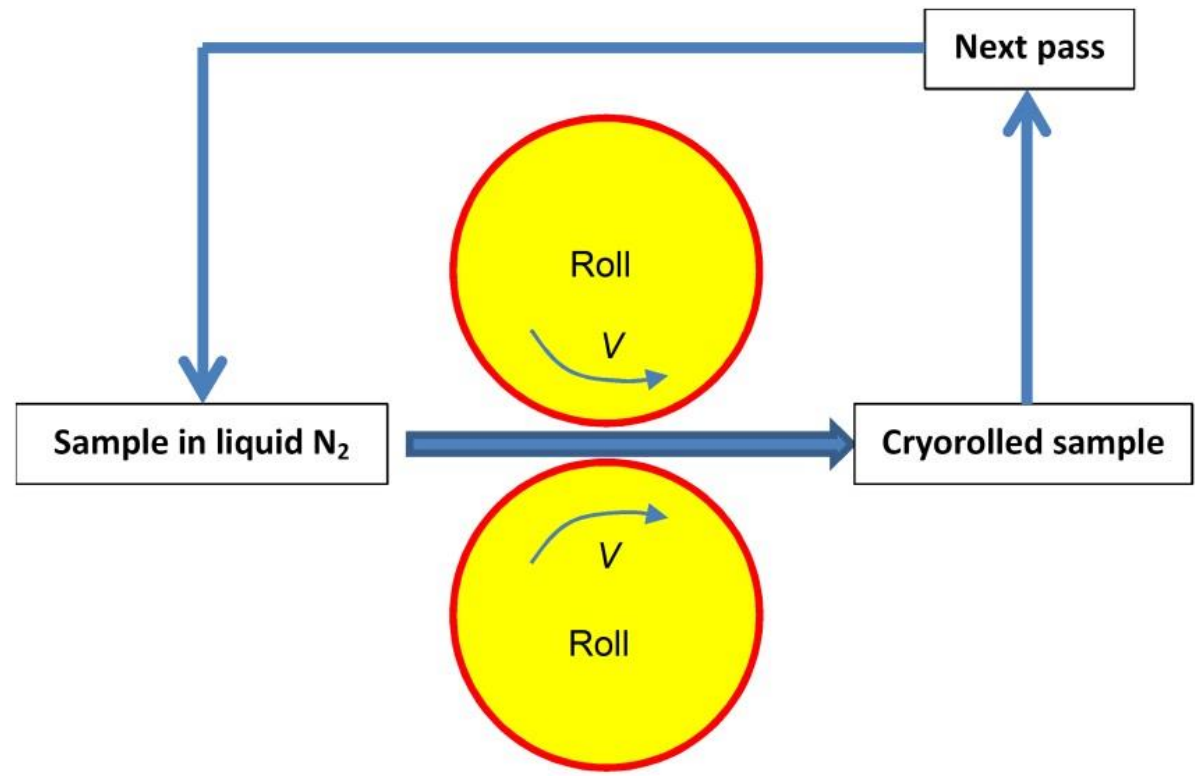

Fig. 5. Cryorolling.

Al alloys show high ductility at cryogenic temperatures. There are many applications of CR for fabrication of UFG/NG Al alloys. ${ }^{[59-70]}$ Optimal CR reduction and subsequent annealing conditions result in ultrafine grains in $\mathrm{CP} \mathrm{Al}$ with both high strength and high ductility. ${ }^{[59]}$ Cryorolled $\mathrm{Al}$ sheets can reach a tensile strength that is $30 \%$ higher compared to $\mathrm{Al}$ sheets SR-processed at room temperature. ${ }^{[60]}$ Under optimal processing conditions, suppression of dynamic recovery during cryogenic deformation results in high defect density, which in turn results in increased nucleation sites during annealing, and leads to finer grains. ${ }^{[61]}$ The effect of annealing on the evolution of microstructure and mechanical properties of Al 5083 alloy by CR was investigated by Lee et al. ${ }^{[62]}$ Optimisation of $\mathrm{CR}$ and subsequent annealing processes resulted in a mixture of equiaxed grains of $<200 \mathrm{~nm}$ and elongated subgrains, exhibiting a good combination of high strength and uniform elongation, as shown in Fig. 6. The cryorolled samples show an increase of at least $10 \%$ in both tensile strength and yield strength of the Al 5083 alloy, compared to those of the room-temperature rolled alloy. Similar results were also obtained by Singh et al. ${ }^{[63]}$ 
The influence of CR and SR at room temperature on the mechanical properties and microstructure of Al 6063 was investigated by Panigrahi et al. ${ }^{[64-67]}$ An enhanced strength (257 MPa) of cryorolled Al 6063 alloy was observed as compared to SR-processed samples (232 MPa). As compared to their coarse-grained counterparts, the high strength UFG metals and alloys often show a decreased tensile ductility. Panigrahi et al ${ }^{[64-67]}$ also found that dislocation accumulation and nanosized precipitates are responsible for enhancing the strength, while a high density of nanosized precipitates and a low dislocation density improve the ductility of the cryorolled Al 6063 alloy subjected to an optimised treatment of short-duration annealing and ageing. The increase in strength and ductility can be attributed to formation of fine precipitates and dynamic recovery effect respectively. The CR technique could also significantly improve the yield stress, ultimate tensile stress, impact energy and fracture toughness of Al 7075. ${ }^{[68,69]} \mathrm{A}$ superior combination of mechanical properties (Yield stress $611 \mathrm{MPa}$ and total elongation 15\%) of Al 7075 can be achieved for specimens which are cryorolled to a true strain of 0.5 followed by natural aging for $1000 \mathrm{~h} .{ }^{[70]}$
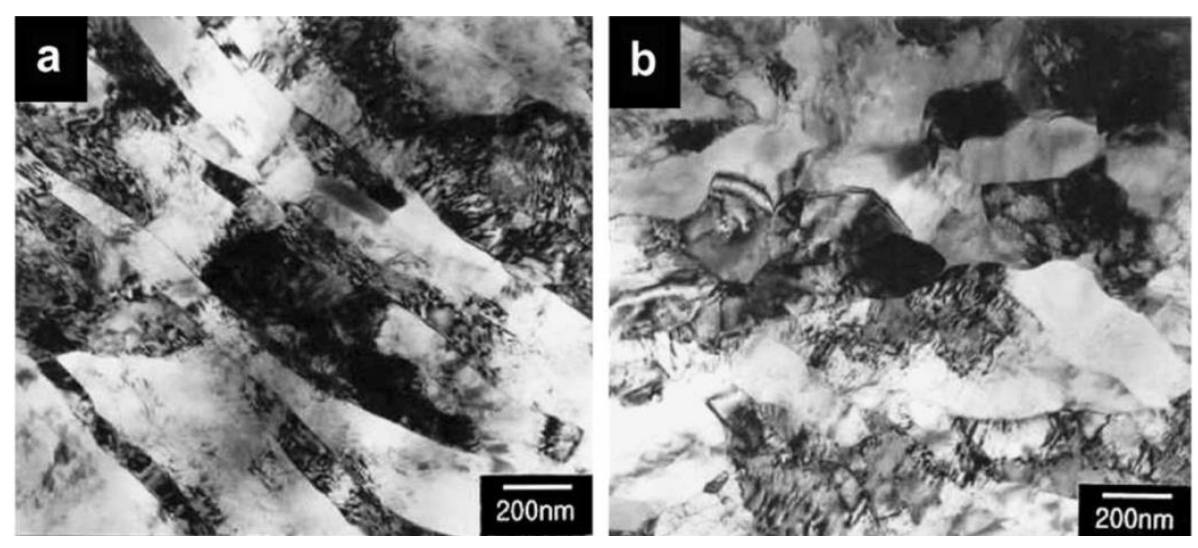

Fig. 6. TEM images of Al 5083 alloy cryorolled with $85 \%$ reduction and annealed at (a) $423 K$ and (b) $473 K$ for $1 h^{[62]}$

The UFG/NG alloys fabricated by CR have potential applications in biotechnology. Trivedi et al ${ }^{[71]}$ studied the potential for orthopedic application of bulk UFG Zr by CR followed by annealing at $673 \mathrm{~K}$ and $723 \mathrm{~K}$ for $30 \mathrm{~min}$. An estimation of surface wettability of the alloy was obtained through measurement of the contact angle. The 
bioactivity of the alloy was studied by incubating stem cells derived from bone marrow. It was found that cryorolled $\mathrm{Zr}$ displayed exceptional in-vitro biocompatibility combined with satisfying bioactivity. In addition, short annealing of the samples was found to result in the formation of multimodal microstructure leading to the best combination of tensile strength and ductility. The UFG/NG grains result in an increase in strength while the coarse grain facilitated good ductility. Shi et al ${ }^{[72]}$ found that cryorolled $\mathrm{Zr}$ showed an extraordinary toughening with increasing strain, as shown in Fig. 7. The increase in the dislocation density results in the enhanced strength, and the motion of pre-existing high-density dislocations at high stress to from nanoscale subgrains and grains contributes to the improved ductility.

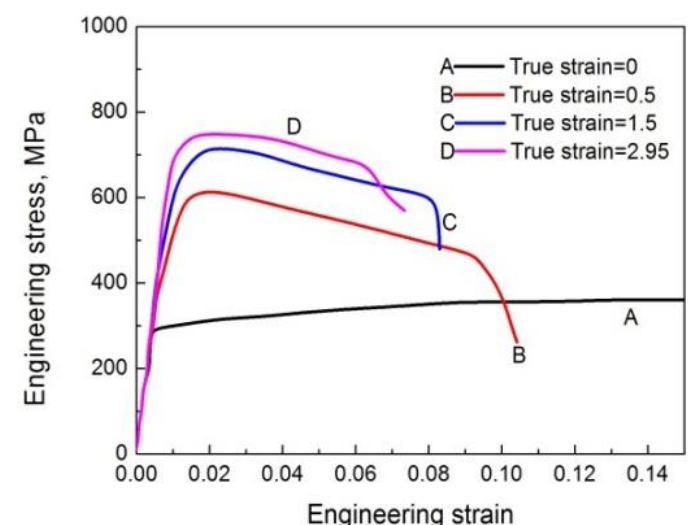

(a)

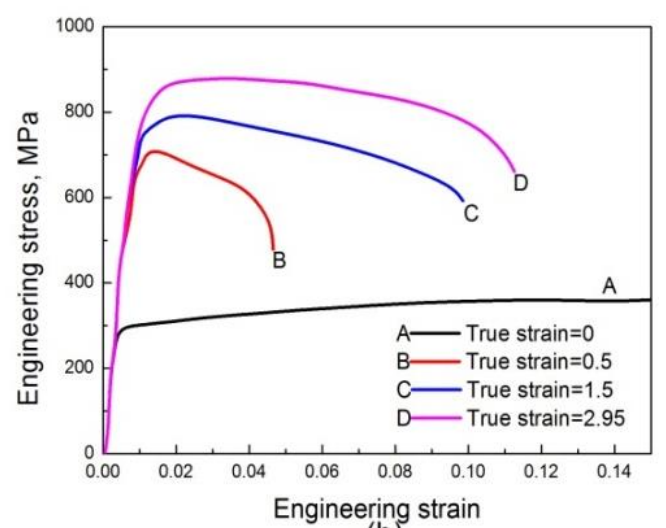

(b)

Fig. 7. Engineering stress vs engineering strain curves of (a) cryorolled and (b) room temperature rolled $\mathrm{Zr}{ }^{\left[{ }^{[72]}\right.}$

CR also finds applications in the fabrication of UFG/NG Ti alloys. During CR, intensive twinning in $\mathrm{Ti}$ accelerates the kinetics of microstructure refinement, and a grain/subgrains size of approximately $80 \mathrm{~nm}$ can be obtained when the rolling reduction ratio reaches $93 \% .{ }^{[73]} \mathrm{CP}$ Ti with a multimodal grain structure can be fabricated by CR followed by low-temperature annealing. ${ }^{[74]}$ This multimodal grain structure Ti showed high yield strength, high uniform elongation and high elongation to failure. The enhancement of strength was resulted from ultrafine equiaxed grains while the increased ductility was derived from a large part of high-angle grain 
boundaries and multimodal grain structure. ${ }^{[74]}$ Zherebtsov et al ${ }^{[75]}$ compared the microstructure evolution of $\mathrm{CP}$ Ti during $\mathrm{CR}$ and SR. At cryogenic temperatures, twinning was more extensive in terms of the duration of the twinning stage and the fraction of twinned grains. A microstructure with a grain/subgrain size of $\sim 80 \mathrm{~nm}$ at cryogenic temperature or $\sim 200 \mathrm{~nm}$ at room temperature was formed during rolling for rolling to a true strain of 2.66. Fig. 8 shows the mechanical properties of samples, in which the ultimate tensile strengths of $1100 \mathrm{MPa}$ or $900 \mathrm{MPa}$ are for the CR- and SR-processed samples respectively.

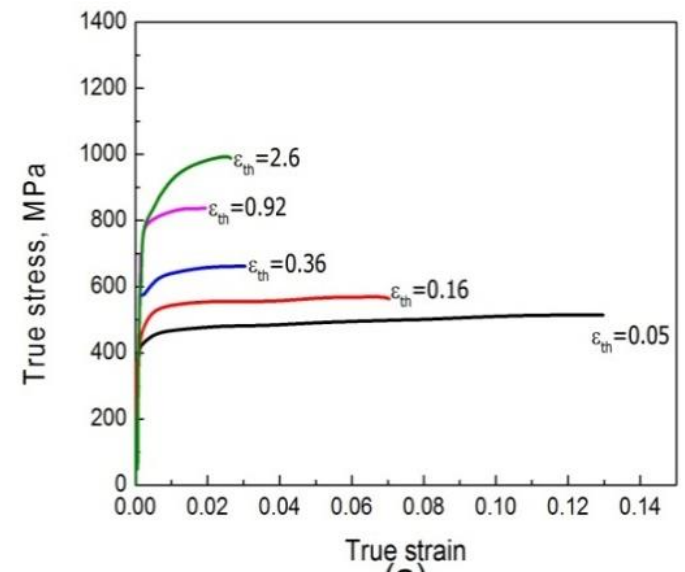

(a)

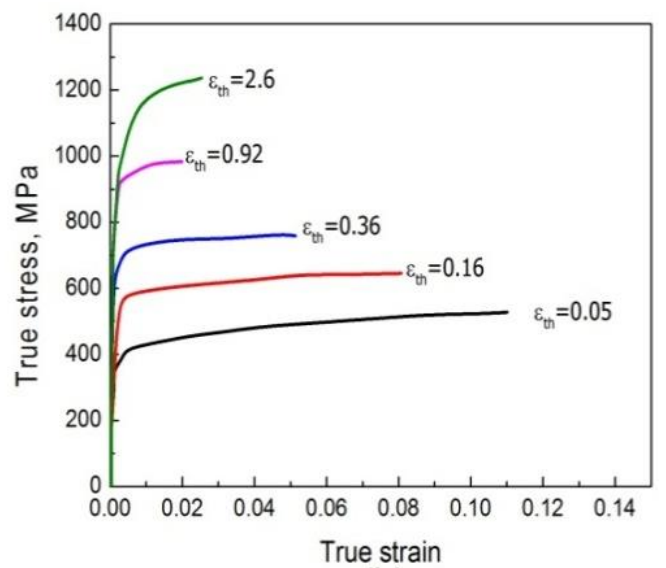

(b)

Fig. 8. True stress vs true strain curves for the CP Ti by (a) room temperature rolling and (b) cryorolling. ${ }^{[75]}$

The CR technique also has been employed to fabricate UFG/NG Cu sheets, ${ }^{[76]}$ steel sheets, ${ }^{[77,78]}$ etc. A high-resolution electron back scattering patterns technique was applied to the quantify grain-structure development and texture evolution during/after $\mathrm{CR}$ of pure $\mathrm{Cu}$ by Konkova et al. ${ }^{[76]}$ The texture contained a pronounced $\left\{\begin{array}{lllll}1 & 1 & 0\end{array}\right\}<1$ $2>$ brass component, which was explained in terms of the suppression of cross-slip at cryogenic temperature. Roy et $\mathrm{al}^{[77]}$ reported a synthesis of nanostructured austenitic AISI 304L stainless steel through CR and reversion annealing in the temperature range of $973 \mathrm{~K}$ and $1073 \mathrm{~K}$. Severe CR promotes twinning in $\gamma$-austenite, which transforms into $a^{\prime}$-martensite with lath thickness of 50-100 $\mathrm{nm}$. The evolution of highly processable bulk nano-austenitic stainless steel with bimodal grain size 
distribution can achieve high strength $(\sim 1295 \mathrm{MPa})$, high ductility $(\sim 0.47)$, and true necking strain $(\sim 0.59)$.

\subsection{Asymmetric Cryorolling (ACR)}

UFG/NG materials often exhibit low tensile ductility at room temperature, which limits their utility. ${ }^{[79,80]}$ Compared with other SPD techniques, the AR and CR techniques can improve both the ductility and strength of UFG/NG materials. Recently, Yu et al ${ }^{[81-84]}$ combined the features of AR and CR to fabricate UFG/NG metals. A schematic illustration of ACR is shown in Fig. 9.

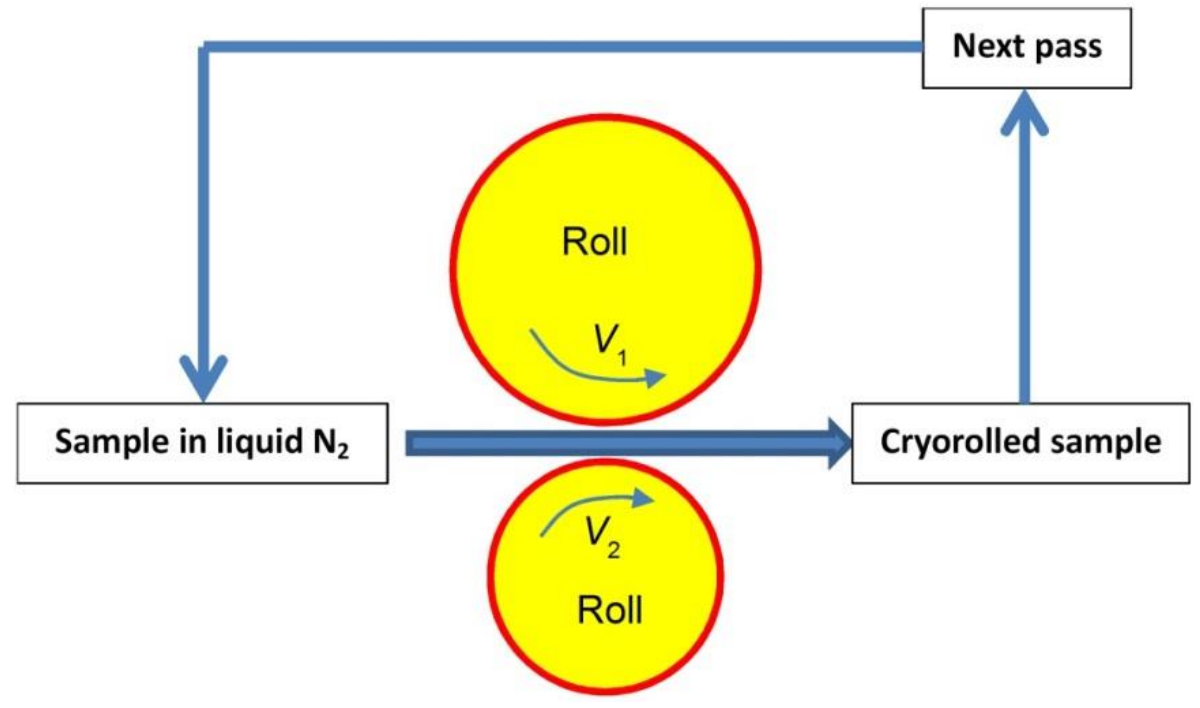

Fig. 9. Asymmetric cryorolling.

The ACR technique has been used successfully to produce UFG Al 1050, ${ }^{[81]} 6061$ ${ }^{[82-83]}$ and $5052^{[84]}$ alloys. Following ACR, the grain size in Al 1050 sheet with the roll speed ratio $\left(R_{\mathrm{RS}}\right) 1.4$ is seen to be much finer than that with the $R_{\mathrm{RS}} 1.1$. After ACR, the grain size is $360 \mathrm{~nm}$ when the $R_{R S}$ is 1.1 , which is reduced to $211 \mathrm{~nm}$ when the $R_{\mathrm{RS}}$ is 1.4. Fig. 10 shows the grain size of CP Al for a variety of SPD techniques. Clearly ACR is more capable of refining grain size compared to ARB, AR and twist extrusion. 


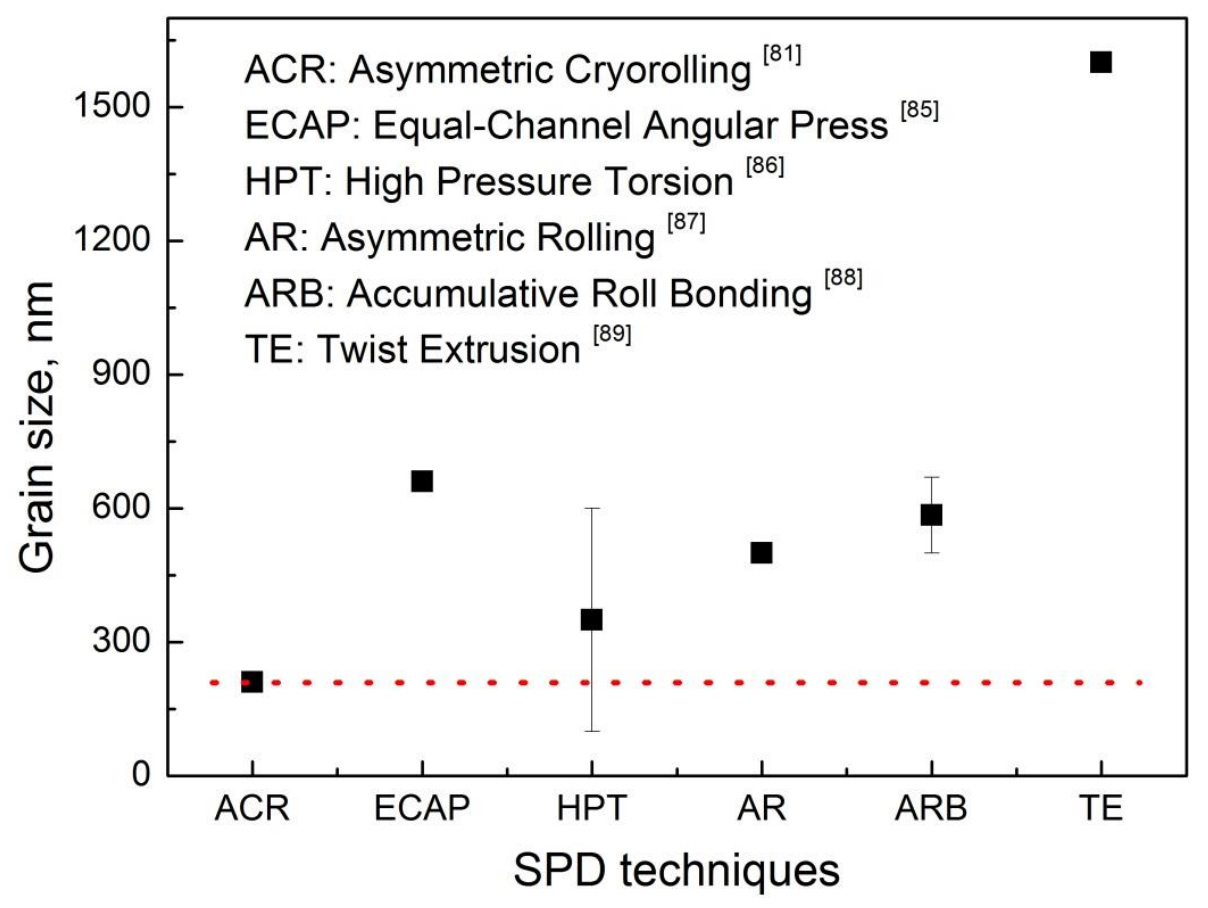

Fig. 10. Grain size of CP Al under different SPD techniques.

An optimised ACR process can result in excellent mechanical properties of UFG materials. Fig. 11 shows the engineering stress vs engineering strain curves of $\mathrm{Al}$ 1050 after $\mathrm{ACR}$ for different $R_{\mathrm{RSS}}$ for the same rolling reduction ratio. Both the strength and ductility of Al 1050 sheets increase with increase in roll speed ratio. The tensile strength of $\mathrm{Al}$ sheets with the $R_{\mathrm{RS}} 1.4$ is $22.3 \%$ greater than that for $R_{\mathrm{RS}} 1.1$, which is $196 \mathrm{MPa}$. 


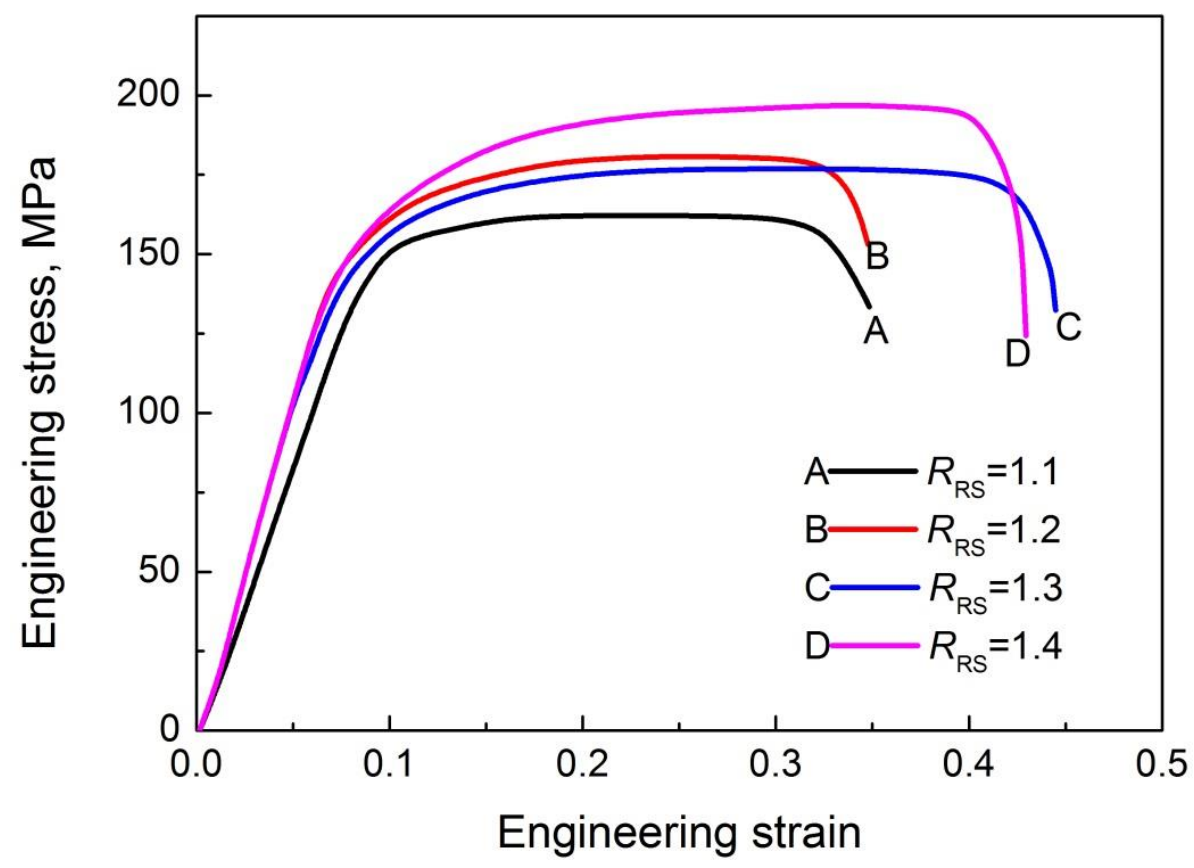

Fig. 11. Engineering stress vs engineering strain curves of Al 1050 after asymmetric cryorolling.

\subsection{Improved Accumulative Roll Bonding}

Cross accumulative roll bonding (CARB) is a rolling technique similar to ARB. The main difference between CARB and ARB is that the CARB process changes the rolling direction by $90^{\circ}$ for each ARB cycle. Fig. 12 shows an illustration of CARB process used for fabrication of an $\mathrm{Al} / \mathrm{B}_{4} \mathrm{C}$ composite sheet. ${ }^{[90]}$ The roll-bonded strip was cut into two strips. After degreasing and brushing, they were stacked over each other and rotated $90^{\circ}$ around the ND axis. The rotated strip was again roll-bonded with $50 \%$ reduction. 


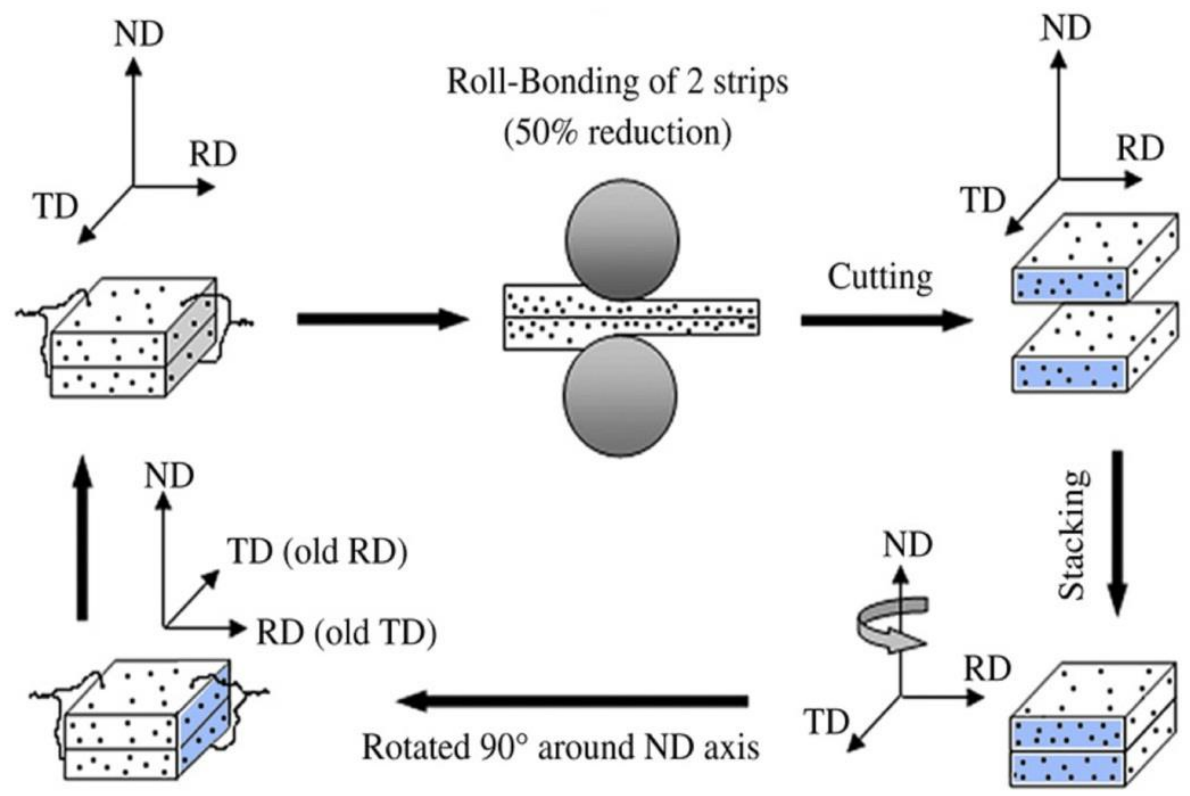

Fig. 12. Illustration of the fabrication of $A l / B_{4} C$ composite sheet by $C A R B .{ }^{[90]}$

Compared with the ARB-processed samples, the CARB-processed samples show enhanced mechanical properties. The CARB process was expected to increase the ductility of severely deformed alloys. ${ }^{[91]}$ In addition, the CARB process can also reduce the plastic anisotropy of the sheets. ${ }^{[92]}$ Ruppert et al ${ }^{[93]}$ compared mechanical properties of ARB-processed and CARB-processed sheets. They found that the strength of CARB-processed Al 6014 samples exceeds the strength of the ARB-processed samples. The first rotation of the sheet was found to be responsible for the additional strength in CARB compared to ARB, due to activation of previously latent slip systems. Alizadeh and Paydar [90, 94, 95] found that good bonding was facilitated between Al layers in the presence of the ceramic particles. They ${ }^{[90,95]}$ found that the dispersion of the $\mathrm{B}_{4} \mathrm{C}$ particles in the composite produced by CARB was more homogeneous than that produced by ARB. Fig. $13{ }^{[95]}$ shows the curves of engineering stress vs engineering strain of $\mathrm{Al} / \mathrm{Al}_{2} \mathrm{O}_{3}$ samples after $\mathrm{ARB}$ and $\mathrm{CARB}$ respectively. The tensile strength and ductility of the CARB-processed composite sheets was higher than that of the ARB-processed composite sheets. In addition, the higher ductility of the CARB-processed samples was confirmed by the SEM observations of fracture surface. 


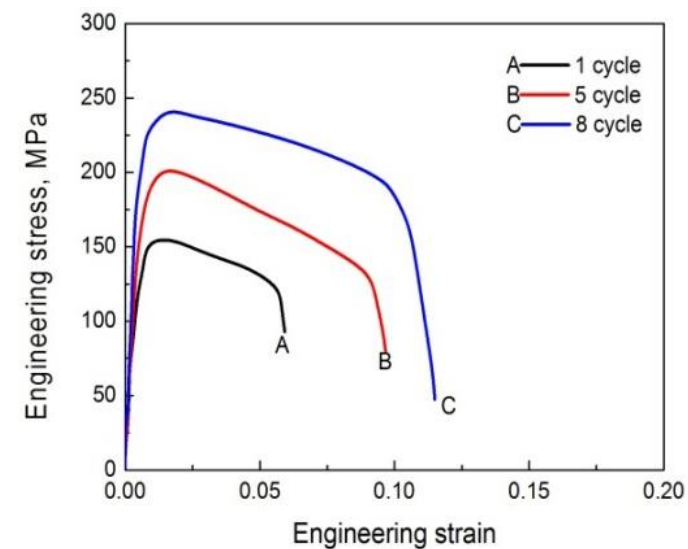

(a)

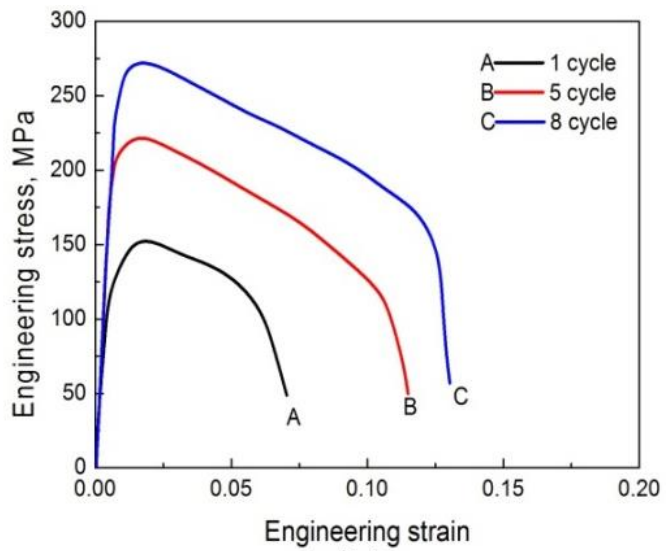

(b)

Fig. 13. Engineering stress vs engineering strain curves of (a) ARB-processed and (b)

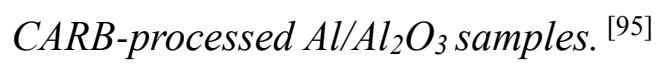

If the rolling reduction ratio is set to $50 \%$, the bonding strength is lower for most of metals when rolled at room temperature, as shown in Fig. 14. ${ }^{[96]}$ Thus, it is necessary to heat most metals before rolling to improve the bonding quality during ARB. However, if the rolling reduction is larger than $75 \%$, a high bonding quality can be achieved. Yu et al ${ }^{[97]}$ developed a 'four-layer accumulative roll bonding' (FL-ARB) technique to improve the bonding quality of layers. During FL-ARB, a sheet is cut into four pieces of equal size. The interfaces between the any two adjacent sheets are degreased and brushed to improve the bond strength. And then the four pieces are neatly stacked before rolling. Compared to ARB, the main merits of the FL-ARB technique are: (i) an enhancement of the interface bonding with a higher rolling reduction ratio in each pass, and (ii) potential application at ambient temperature. The FL-ARB technique has also been used to fabricate NG IF steel with grain sizes of smaller than $100 \mathrm{~nm} .{ }^{[98]}$ With increase in the number of FL-ARB cycles, the dislocation density increased from $2.02 \times 10^{15} \mathrm{~m}^{-2}$ for the original sample to $9.47 \times 10^{15} \mathrm{~m}^{-2}$ after the fourth cycle. The yield strength of the IF steel after the fourth cycle was 10.8 times (909 MPa) higher than that of the original sample (84 MPa). 


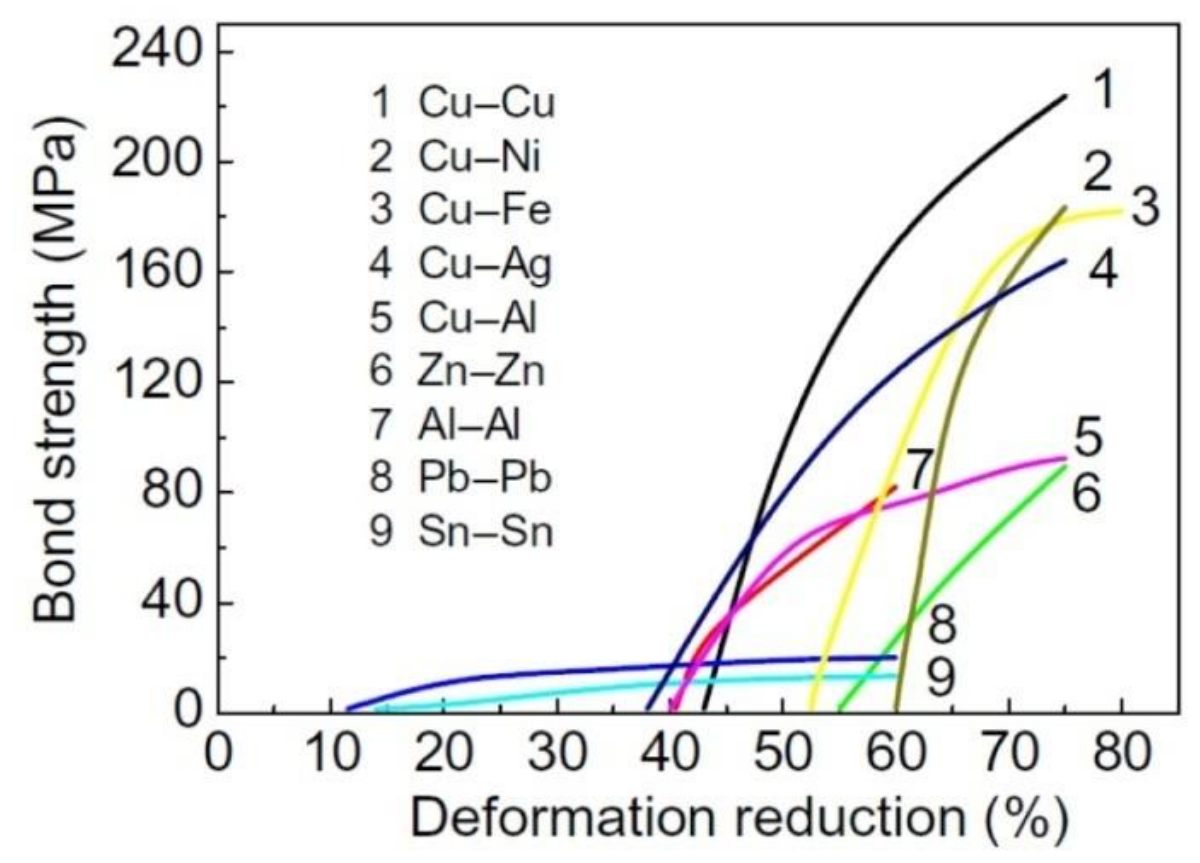

Fig. 14. Bond strength vs reduction ratio during cold roll bonding.

\subsection{Skin-Pass Rolling}

'Gradient structure' exists in nature such as bamboos and teeth, which is a typical structure that has evolved over several million years to allow biological systems strong and tough enough to exist in nature. Producing a nanograined layer at the material surface can result in a considerable enhancement in its mechanical properties and thereby its performance. Recently, gradient microstructures, in which the UFG/NG grains gradually change into coarse grains from sample surface to sample core, are revealed to possess improved ductility and strength. ${ }^{[99-103]}$ For nanogradient $\mathrm{Cu}$, both hardening and softening occur concurrently in the gradient microstructure, and the dominant deformation mechanism changes gradually from dislocation slip to grain boundary migration as the grains become smaller. ${ }^{[99,100]}$ The strain hardening caused by a change in stress states and a macroscopic strain gradient was also considered as a mechanism to improve the ductility and strength of IF steel. ${ }^{\text {[101] }}$

Skin-pass rolling (SPR) ${ }^{[104-108]}$ is usually the final stage for fabricating cold-rolled sheets. This process has a significant effect on mechanical properties including Lüder band prevention, ${ }^{[109]}$ strip flatness, surface topography, etc. The reduction ratio is very 
small $(<1 \%)$ during SPR which is different from those in conventional sheet rolling. In practice, SPR is carried out by applying a skin-pass lubricant with very low lubricating ability or in a dry friction condition for preventing adhesion between the sheet and roll and erode on the material surface after rolling, to cleanse the roll surface. Recently, a 4-high multifunction rolling mill was used to fabricate nanogradient $\mathrm{Al}$ sheets. ${ }^{[110]}$ The thickness of the $\mathrm{Al} 1060$ sheets before rolling was 1.5 $\mathrm{mm}$, which was reduced to $1.1 \mathrm{~mm}$ by SR and SPR (40 passes) respectively. Fig. 15a shows an illustration of the SPR technique, and Fig. 15b shows an illustration of gradient sheets. ${ }^{[10]}$
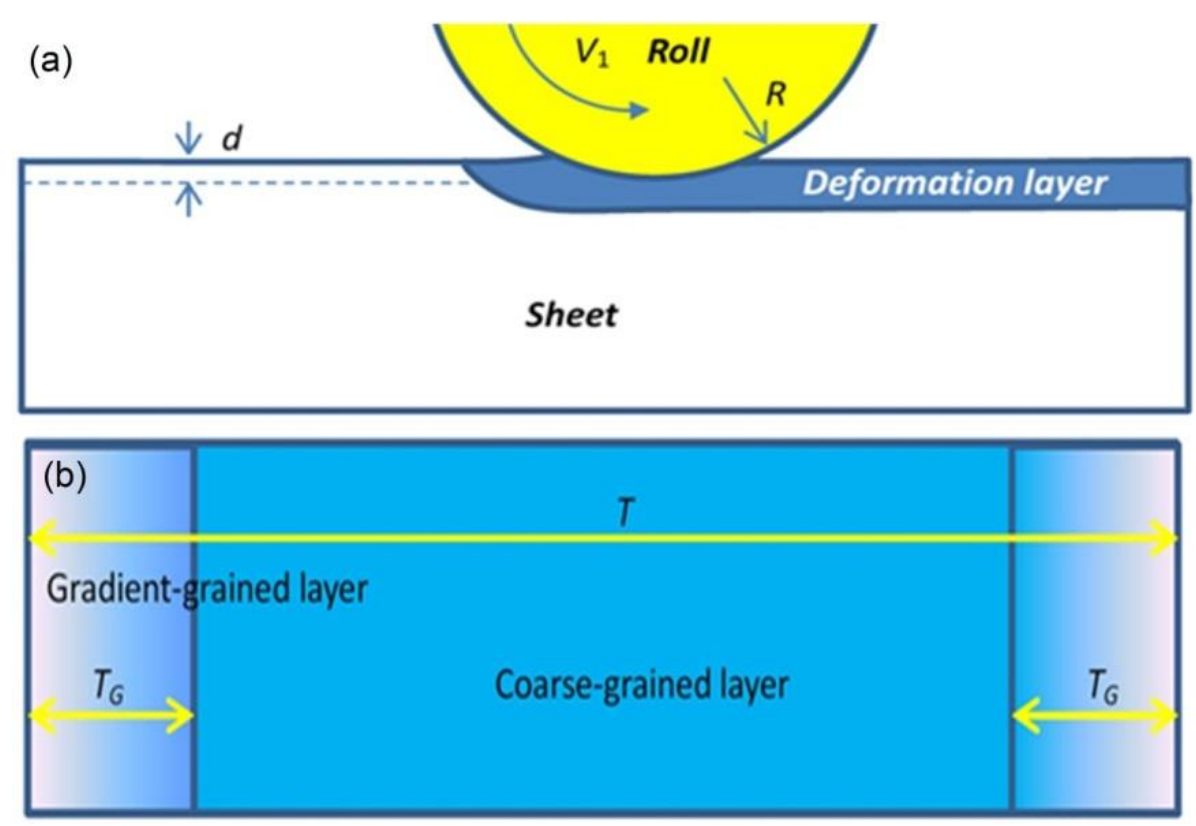

Fig. 15. (a) Illustration of skin-pass rolling technique, (b) illustration of gradient sheets.

Fig. $16^{[110]}$ shows the mechanical properties of the sheets during a tensile test. The yield stress of SPR-processed sheets is slightly lower than that of sheets subjected to cold rolling. However, as shown in Fig. 16(c), the uniform strain of cold rolled sheets is 0.05 , which increases to 0.12 for the sheets processed by SPR. It is obvious that SPR-processed have more desirable qualities such as enhanced ductility without sacrificing the yield strength compared to cold rolling. 

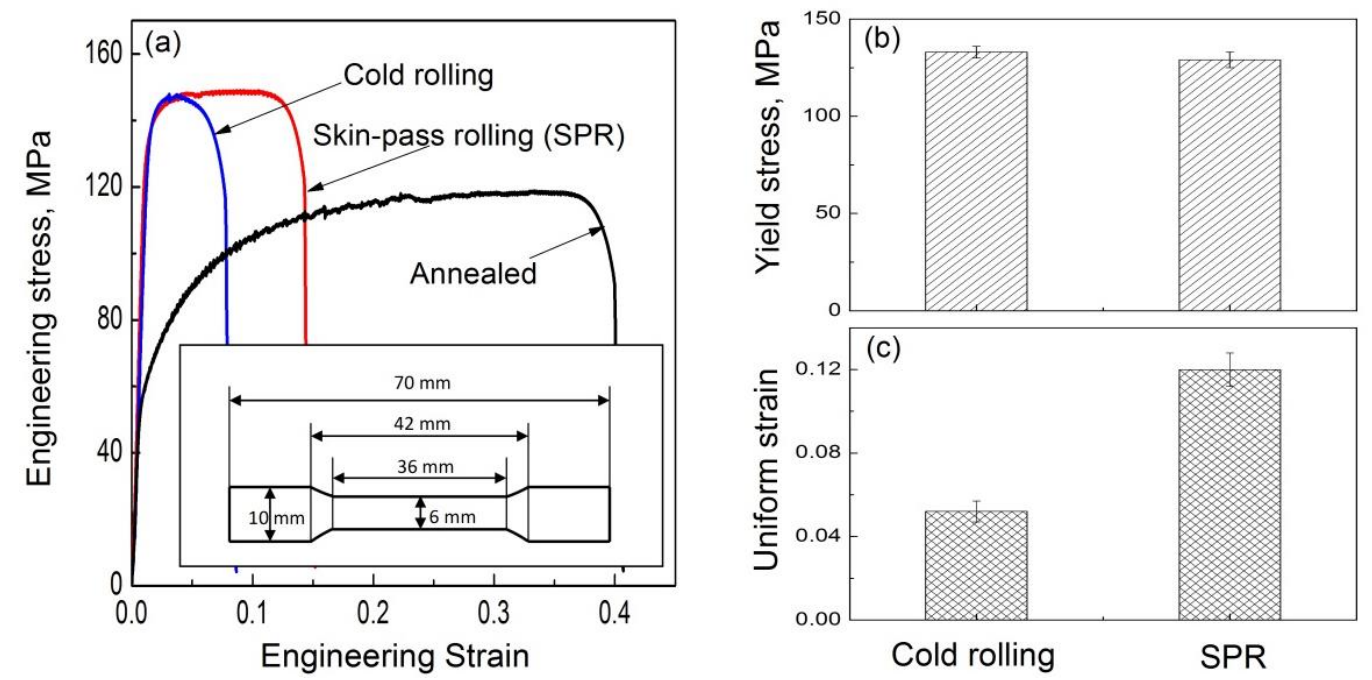

Fig. 16. Mechanical properties of Al 1060 sheets during tensile testing. (a) curves of engineering stress $v s$ engineering strain, (b) yield stress for cold rolling and $S P R$, (c) uniform strain for cold rolling and SPR.

\subsection{Rolling Combined with Other SPD Techniques}

\section{1) ECAP \& Rolling}

ECAP has been widely used to fabricate UFG/NG bulk metals. ${ }^{[7,9]}$ Combining the features of ECAP and rolling, the mechanical properties of UFG/NG metals can be further optimised. Fig. $17^{[111]}$ shows the samples subjected to ECAP followed by rolling.

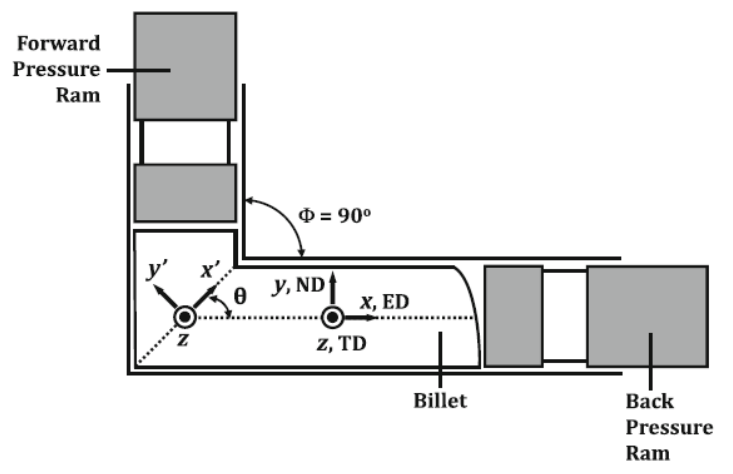

(a)

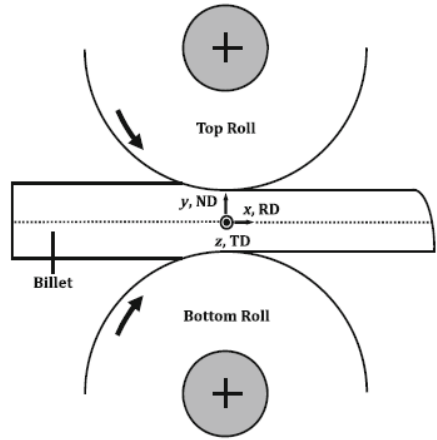

(b)

Fig. 17. Illustration of ECAP processes followed by cold rolling. (a) ECAP-processed sample with the three orthogonal directions, (b) ECAP-processed sample during cold rolling. ${ }^{[111]}$ 
There are many studies on (ECAP+rolling) on the $\mathrm{CP} \mathrm{Cu}$. The rolling operation is found to transform the reasonably equiaxed structure after ECAP into a lamellar structure with a finer boundary spacing. Stepanov et al ${ }^{[112]}$ found that the $180 \mathrm{~nm}$ boundary spacing after 10 ECAP passes decreased to $110 \mathrm{~nm}$ after rolling of $\mathrm{CP} \mathrm{Cu}$, as shown in Fig. 18. The yield strength was improved by $\sim 100 \mathrm{MPa}$ after rolling caused by finer boundary spacing as stated by the Hall-Petch relationship. The mechanical properties of $\mathrm{CP} \mathrm{Cu}$ sheets can also be optimised by ECAP, intermediate annealing and cold rolling. ${ }^{[113]}$ ECAP enhanced the dislocation density by spreading the recrystallization nuclei during annealing. Ranjbar Bahadori et al ${ }^{[114,115]}$ studied the relationship between microstructure and mechanical properties of $\mathrm{CP} C u$ processed by ECAP and subsequent cold rolling. They found that adding CR to ECAP could improve both the strength and ductility significantly. Cold rolling on ECAP-processed specimen changed the microstructure from equiaxed grains with rather thick boundaries to an elongated structure with lamellar boundaries. In addition, it not only decreased the mean grain size but also lessened the grain size diversity between the upper and lower surfaces, leading to a more homogeneous structure. The enhancement in strength is attributed to grain refinement and internal stress augmentation, while the increase in ductility of workpiece is due to an increase in the microstrain.
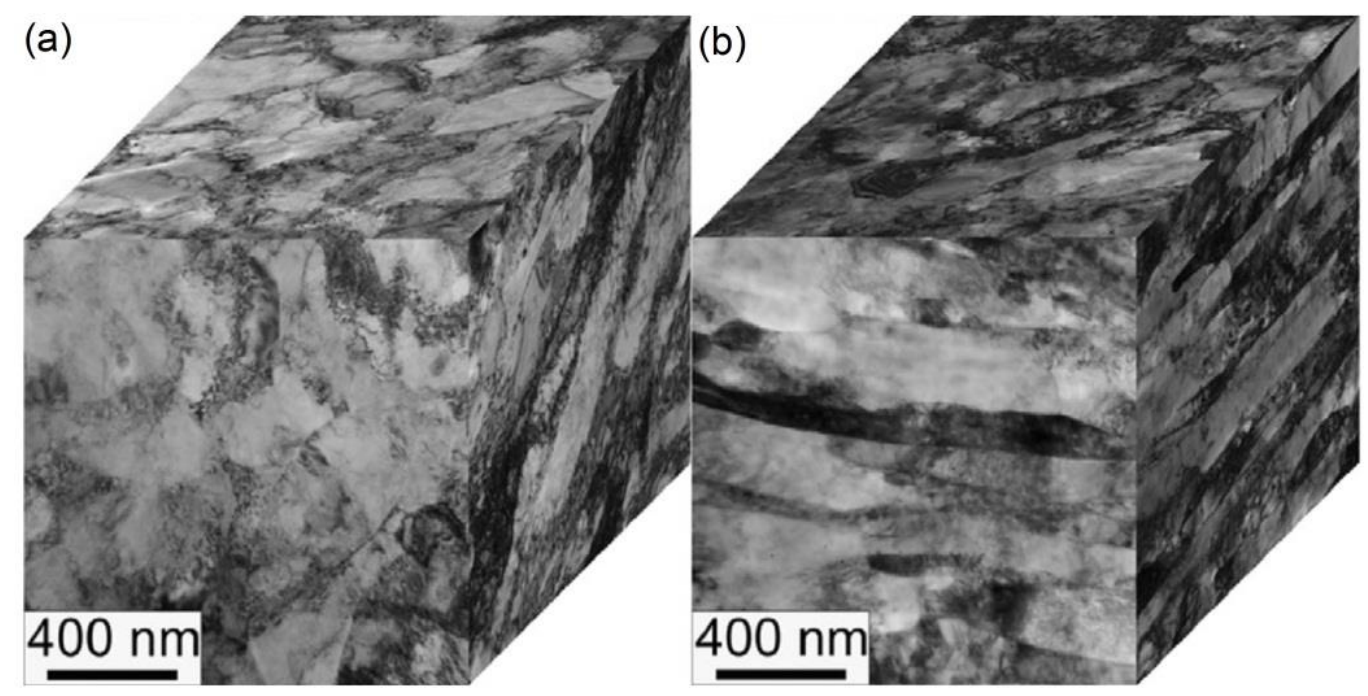

Fig. 18. TEM images of Cu after (a) 10 ECAP pass, (b) 10 ECAP pass + rolling. ${ }^{[12]}$ 
A combination of ECAP and rolling can improve the mechanical properties of $\mathrm{Al}$ alloys. A commercial Al-Mg alloy was subjected to four passes of ECAP followed by rolling with a $70 \%$ thickness reduction by Park et al. ${ }^{[116,117]}$ The influence of post-ECAP rolling on the deformation behavior of the samples at $723 \mathrm{~K}$ were studied. The high strain rate superplastic elongation was remarkably enhanced during Post-ECAP rolling, as shown in Fig. 19. The main findings were: (1) post-ECAP rolling leaded to an ultrafine elongated substructure delineated by lamellar boundaries, and (2) the dislocation viscous glide played key role in the deformation of the ECAP alloy while the grain boundary sliding governed the deformation of the $(\mathrm{ECAP}+\mathrm{cold}$ rolled) sample, resulting in a comparatively uniform deformation throughout the sample.
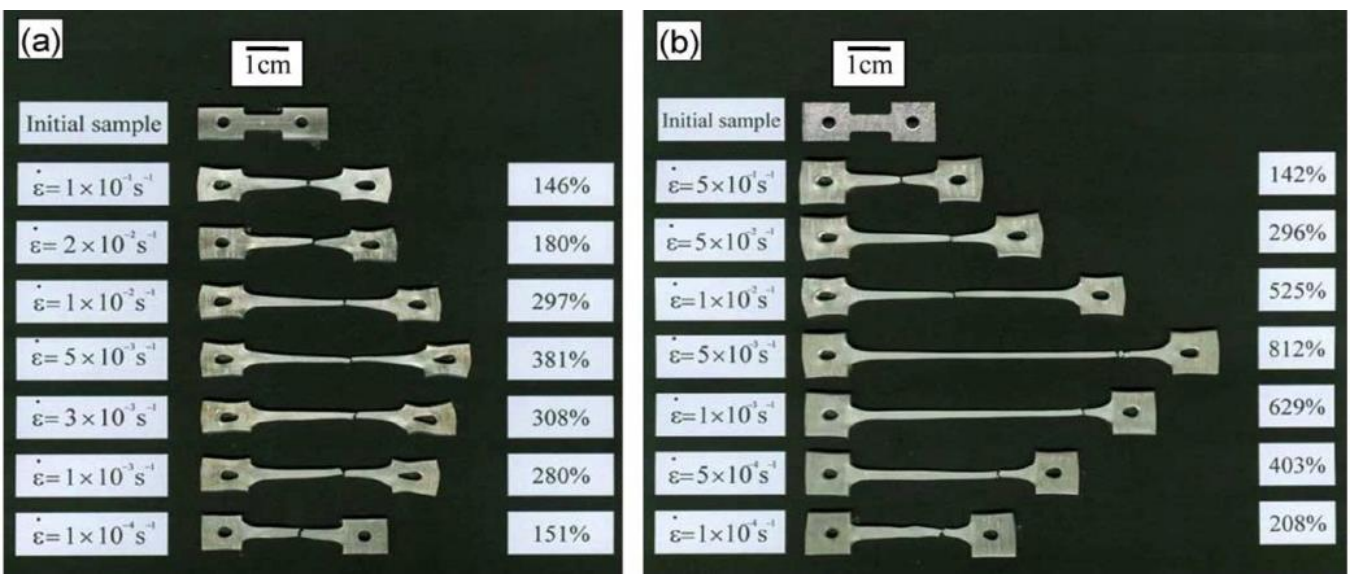

Fig. 19. Shape of (a) the ECAP-processed samples and (b) the ECAP $+C R(70 \%)$ samples after tensile test at $723 \mathrm{~K} .{ }^{[116]}$

Post-ECAP rolling of Mg alloys can enhance their hydrogen storage capacity ${ }^{[118]}$ and mechanical properties. ${ }^{[119,120]}$ The cold rolling may reduce the extent of unfavorable texture $\left(\begin{array}{lll}1 & 0 & 1\end{array}\right)$ and produce a favorable texture $\left(\begin{array}{lll}0 & 0 & 2\end{array}\right)$. This may result in the fastest $\mathrm{H}$-absorption kinetics and capacity compared to samples subjected to ECAP only, as shown in Fig. 20. ${ }^{[118]}$ Post-ECAP rolling led to an average grain size $\sim 8-10 \mu \mathrm{m}$ with basal texture fiber parallel to ND from ECAP-processed sample of 12-18 $\mu \mathrm{m} .{ }^{[120]}$ The microstructural features of ECAP-processed and room temperature-rolled pure $\mathrm{Mg}$ indicate that the dynamic recrystallization mechanism is 
made up of continuous dynamic recovery and recrystallization in regions where the prismatic/pyramidal slip activities are predominant and discontinuous dynamic recrystallization in other regions where the basal slip activity is higher. Yuan et al ${ }^{[119]}$ used ECAP and subsequent cold rolling to fabricate a ZK60 Mg alloy sheet with a superior combination of ultrahigh strength and good ductility. The post-ECAP rolling almost doubled the yield strength of ECAP alone.

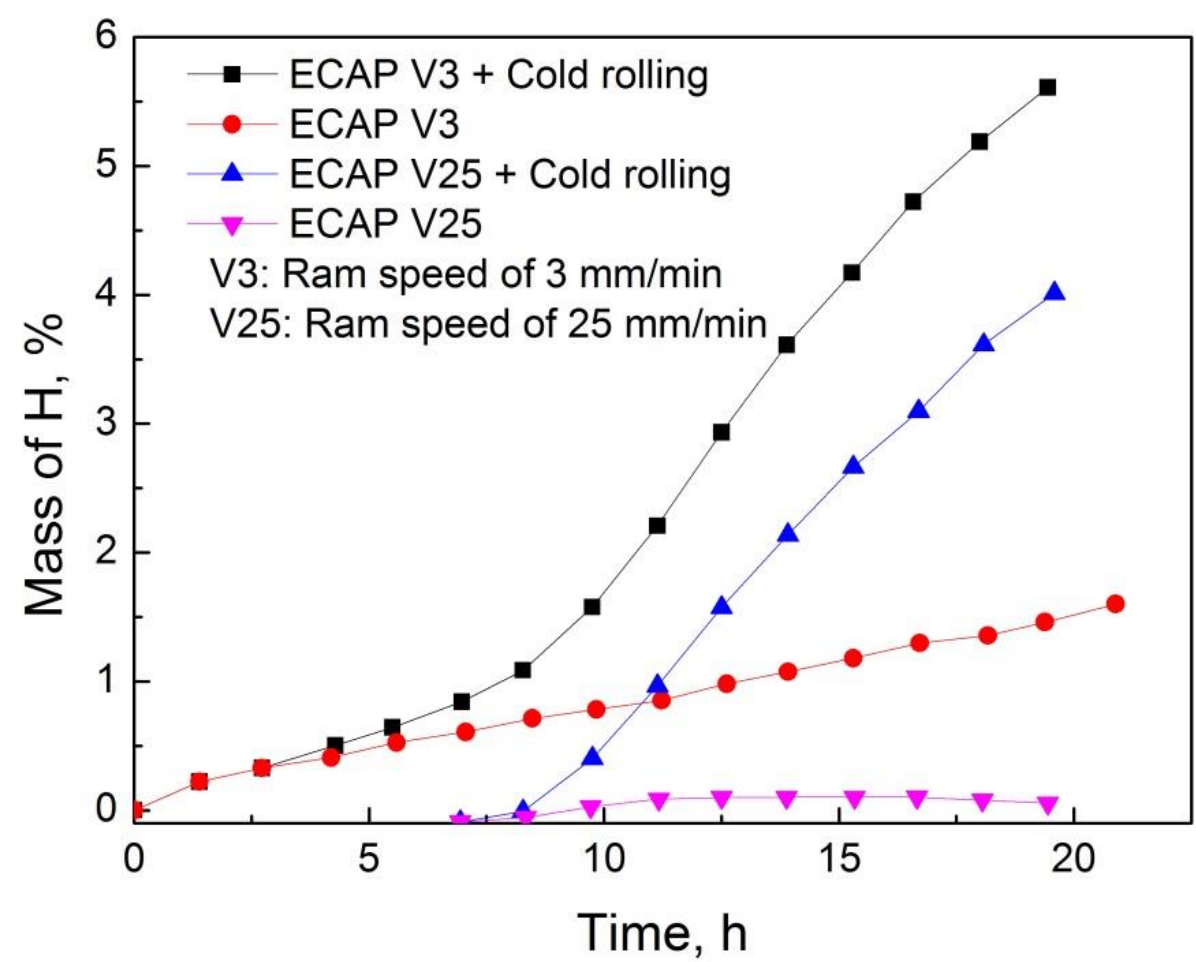

Fig. 20. First hydrogen absorption kinetics at $623 \mathrm{~K}$ and under hydrogen pressure of 15 bars. ${ }^{[118]}$

A combination of ECAP and rolling techniques can significantly improve the mechanical properties of Ti-stabilized IF steel ${ }^{[111]}$ and Ti alloys. ${ }^{[121,122]}$ Ti-stabilized IF steel samples were subjected to eight passes of ECAP followed by cold rolling with up to $95 \%$ thickness reduction by Hazra et al. ${ }^{[111]}$ The post-ECAP microstructure contains equiaxed subgrains/grains and elongated subgrains and grains aligned along the direction of imposed negative simple shear. As the rolling reduction increases, the boundaries change progressively into aligned to the rolling direction with a microshear banded lamellar substructure evolving after 95\% cold rolling. Cold rolling results in a strength gain $\left(\sigma_{0.2}=\right.$ from $607 \mathrm{MPa}$ to $1097 \mathrm{MPa}$ and $\sigma_{\mathrm{UTS}}=$ from $689 \mathrm{MPa}$ 
to $1280 \mathrm{MPa}$ ) and a reduction in total elongation from $7 \%$ to $3 \%$. Hajizadeh and Eghbali ${ }^{[122]}$ investigated the microstructure and mechanical properties of $\mathrm{CP} \mathrm{Ti}$ after processing by warm ECAP and CR with a thickness reduction 35\%. The curve of engineering strain vs engineering stress of samples under various conditions are shown in Fig. 21. After 10 passes of ECAP, an UFG structure with average grain size of $213 \mathrm{~nm}$ was achieved with mainly equiaxed grains. Subsequent cryorolling led to further refinement and decreased the grain size to $114 \mathrm{~nm}$ with lamellar structure and higher dislocation density.

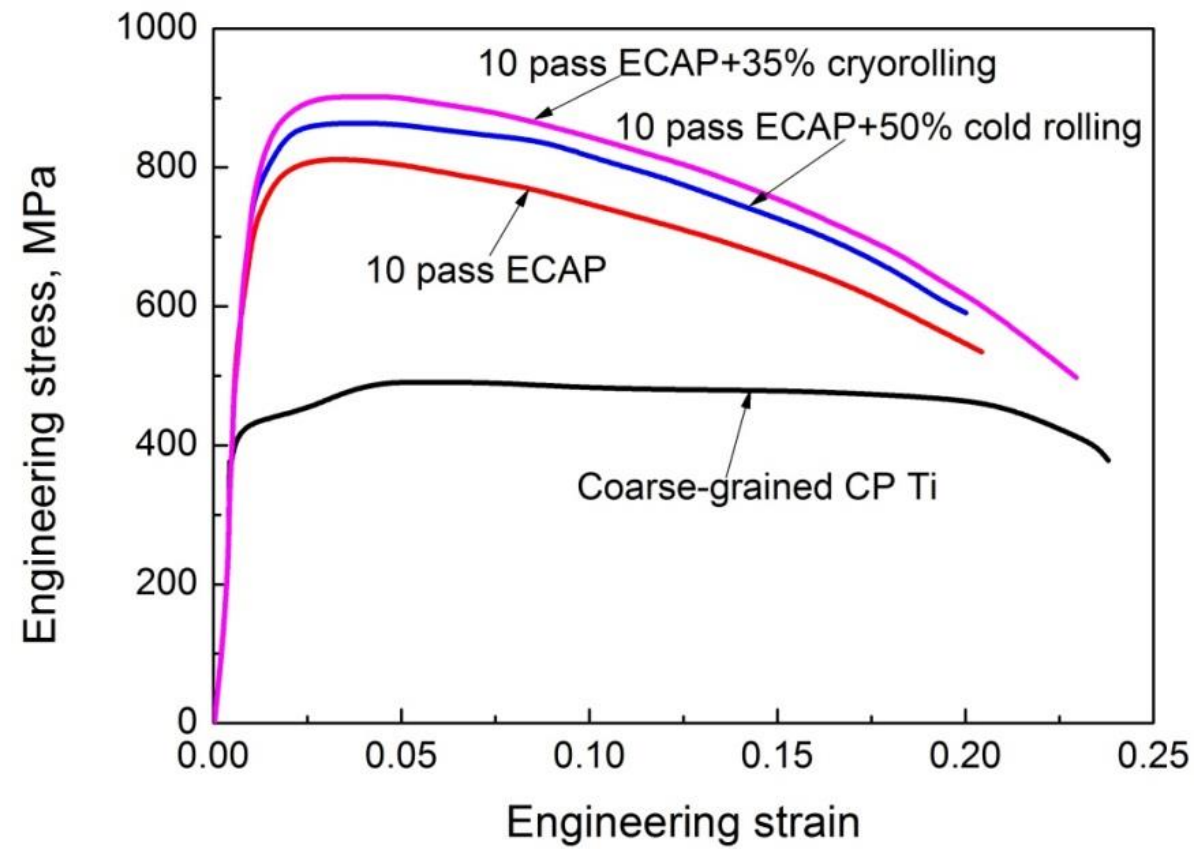

Fig. 21. Engineering stress vs engineering strain curves of CP-Ti obtained under different processing. ${ }^{[122]}$

\section{2) HPT \& Rolling}

HPT is an SPD technique that has been widely used to produce UFG/NG metal disks in large quantities. Recently, some researchers ${ }^{[123-125]}$ have reported a combination of HPT and rolling to further improve the mechanical properties of the products. Fig. 22 shows an illustration of HPT followed by rolling. The rolling enables: (1) production of longer samples, and (2) improvement in the homogeneity of the samples after HPT. Generally, HPT can only produce small disc-shaped samples, which can be enlarged many times by rolling. Also, HPT-processed samples are generally harder at the edge than in the core. This inhomogeneity can be reduced 
by rolling.

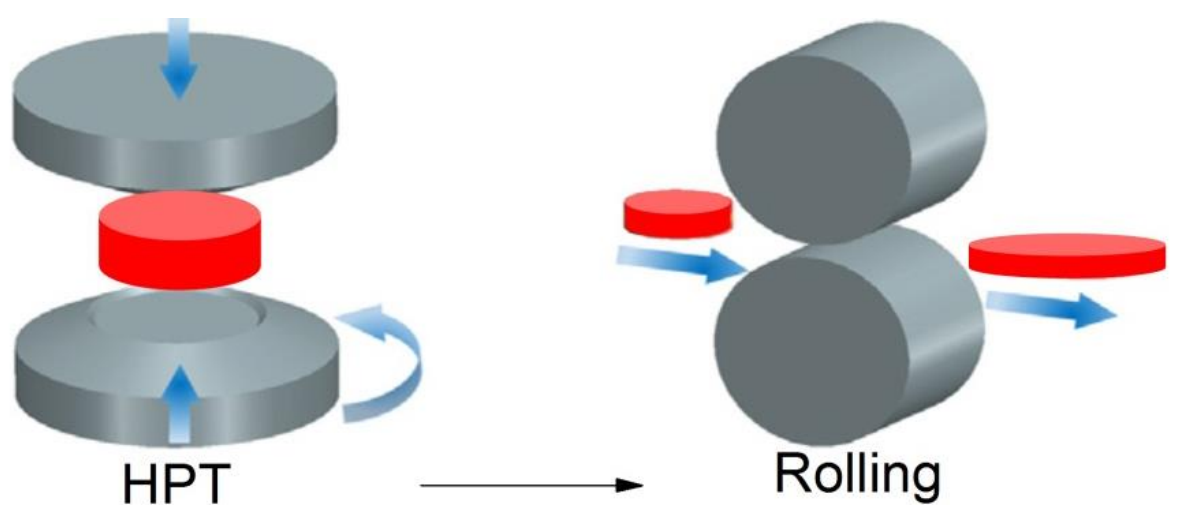

Fig. 22. Illustration of fabrication of CG/NS/CG sandwich materials.

The microstructure of HPT-processed samples will evolve to a new steady state with a larger grain size after cold-rolling. ${ }^{[123]}$ Tao et al ${ }^{[124]} \mathrm{HPT}-$ processed a Cu-7 wt\% Al alloy with an initial grain size of $\sim 67 \mu \mathrm{m}$. After 6 revolutions under an imposed pressure of $5.0 \mathrm{GPa}$, the grain size was refined to $\sim 63 \mathrm{~nm}$. Following HPT processing, the disks were rolled and then annealed for periods of 90 or $120 \mathrm{~min}$ at selected temperature from 200 to $310{ }^{\circ} \mathrm{C}$. It was found that annealing at $250{ }^{\circ} \mathrm{C}$ for $120 \mathrm{~min}$ produces the highest measured strength. This can be attributed to the formation of nanoscale annealing twins, as shown in Fig. 23. The (HPT+rolling) process was also used to fabricate gradient structure materials. ${ }^{[125]}$ A laminate structure with a nanostructured $\mathrm{Cu}-10 \mathrm{Zn}$ layer sandwiched between two coarse-grained $\mathrm{Cu}$ layers was fabricated by HPT, rolling and annealing by Ma et al. ${ }^{[125]}$ They found that mechanical incompatibility between the different layers during tensile deformation produced high strain hardening that led to a tensile ductility higher than what was predicted using the rule of mixtures. In their sample, the difference between the hardness at the edge and in the sample core was found to be $600 \mathrm{MPa}$. However, the evolution of the microstructure of HPT-processed samples during rolling was not analyzed in Refs. $[124,125]$. 


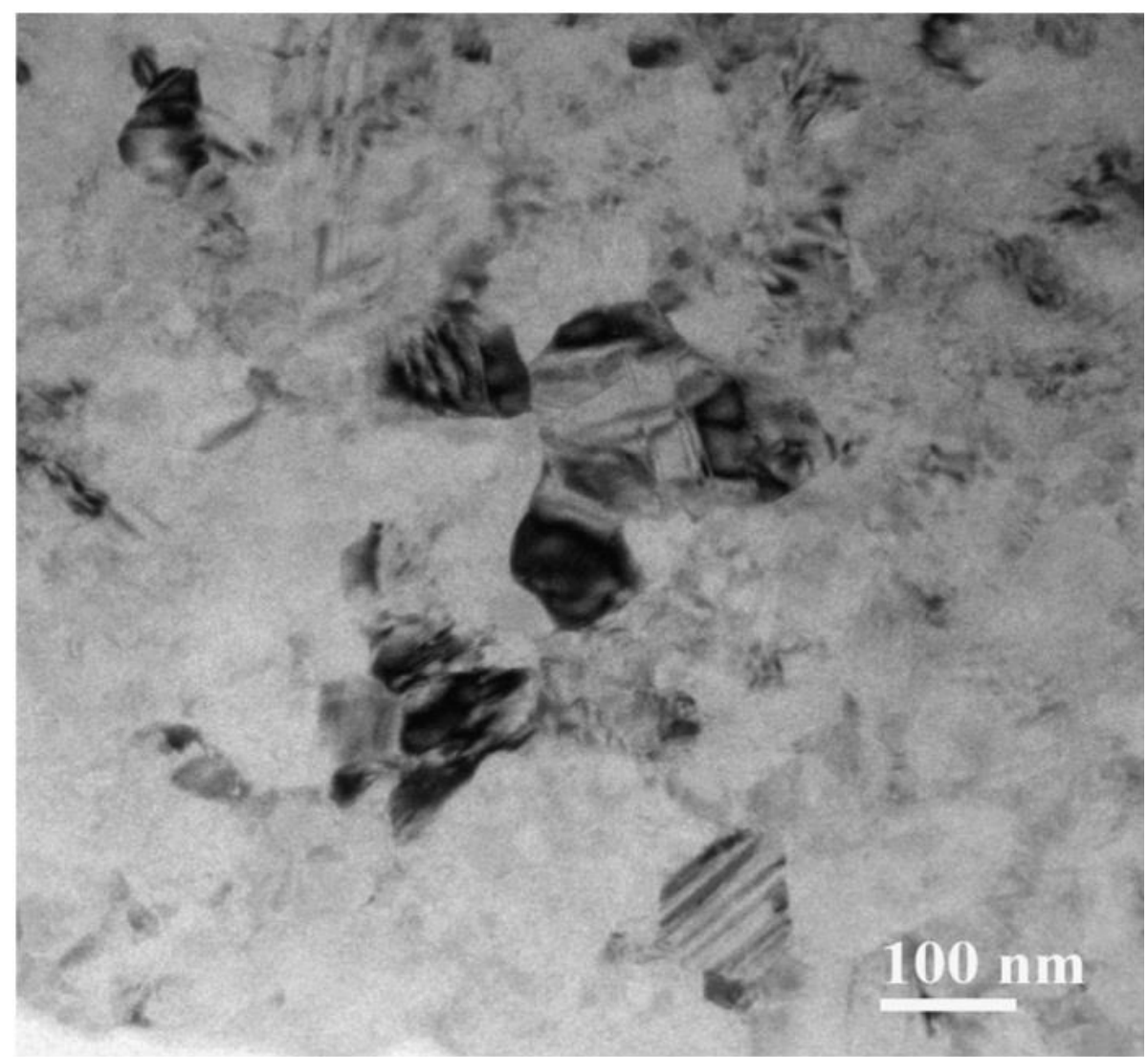

Fig. 23. TEM image of the alloy annealed at $493 \mathrm{~K}$ for 90 min showing grains with twins. ${ }^{[124]}$

\section{3) ARB \& Rolling}

$\mathrm{ARB}$ is an SPD technique which has been used to produce sheets of alloys and composites. In $\mathrm{ARB}$, due to the set reduction ratio (50\%), the bonding quality is not very good, as shown in Fig. 14. After the ARB process, subsequent rolling can improve the bonding quality of the interface, and also improve the mechanical properties of the sheets. Fig. 24 shows an illustration of a combination of ARB and subsequent rolling. ${ }^{[126]}$ 

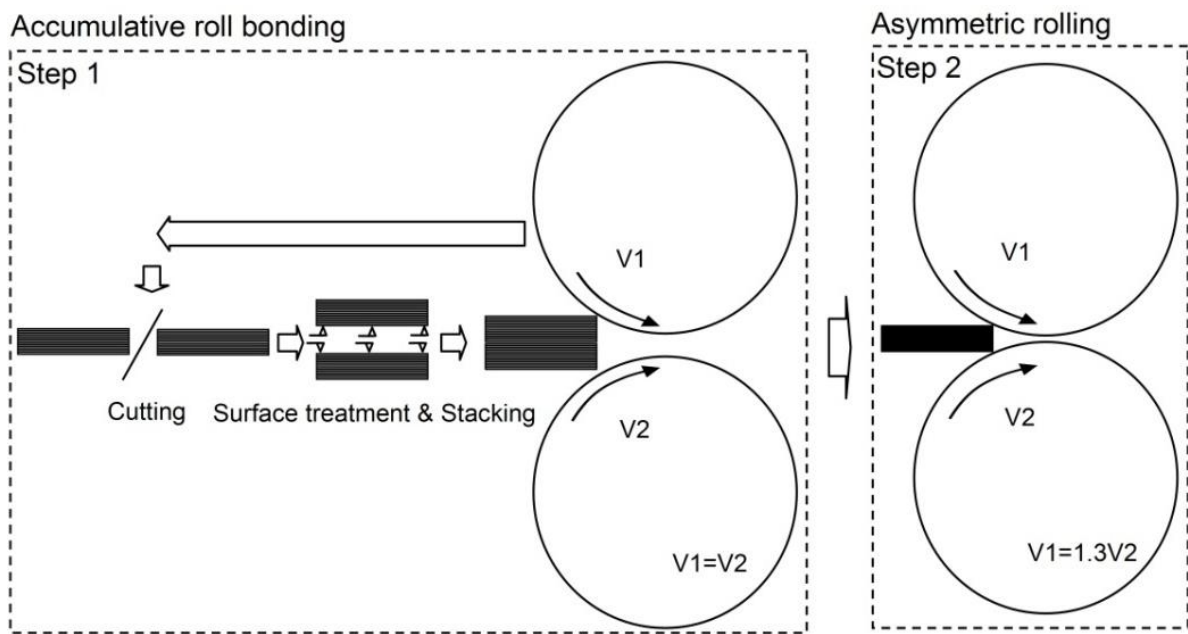

Fig. 24. Illustration of ultrathin foils by $A R B \&$ asymmetric rolling.

Subsequent rolling can improve the bonding strength of ARB-processed sheets. Ruppert et al ${ }^{[127]}$ subjected crossed ARB samples to 1 pass of cold rolling, in order to reduce the impact of weak bonding on the ultimate tensile strength, while still maintaining the high strength. Experimental results revealed improved bonding with no necking of the individual layers after tensile testing. Yu et al ${ }^{[126,128]}$ studied the bonding strength of ultrathin UFG bimetal foils produced using ARB followed by AR. The interface bonding strength was found to increase as the number of rolling passes increased. TEM inspection showed that the interface quality is best when the roll speed ratio is 1.2. There were no noticeable residual voids at the interface of the A11050/A16061 bimetallic foils for this roll speed ratio; however, residual voids were observed when the roll speed ratio was 1.0 or 1.4, as shown in Fig. 25. 

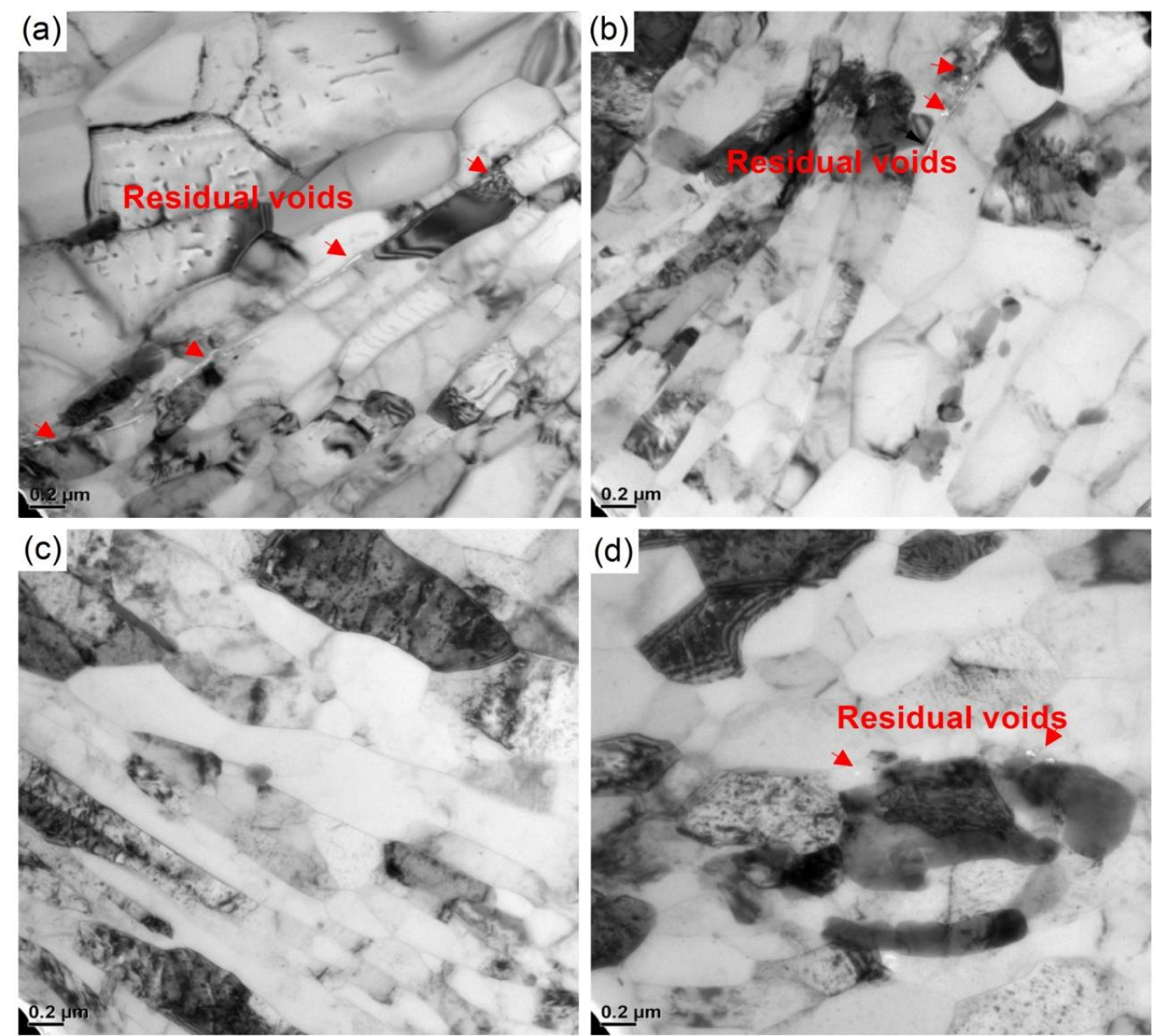

Fig. 25. TEM images of samples around the interface of Al1050/Al6061, (a) ARB processed sample, $(b) \sim\left(\right.$ d) ratios of rolls speed 1.0, 1.2, and 1.4. ${ }^{[126]}$

Post-ARB rolling can improve the mechanical properties of ARB-processed sheets. Compared to ARB-processed sheets, subsequent cold rolling at small strain $(10 \%$ and $15 \%)$ results in softening and higher elongation. However, subsequent cold rolling at large strain $(50 \%)$ leads to remarkable hardening. ${ }^{[129]}$ Dislocations are induced in subsequent cold rolling processing. With increased reduction ratio during rolling, the interior dislocation density increases. In addition, when the strain is increased from 15\% to $50 \%$, the dislocation configuration is changed. At small strain, the interior dislocations occur mainly as loose dislocations that are assumed to be free to move for an induced stress. At large strain, the dislocations constitute networks and tangles. The difference of the dislocation structure under different strain results in the transition from softening to strengthening. When the reduction ratio is less than $50 \%$, the 
strength of foils increases but the ductility reduces. ${ }^{[130]}$ However, with further increase in the rolling reduction ratio, both the strength and the ductility of foils increase. ${ }^{[131]}$ Most of the laminate-structured grains were further refined in the AR process. But some of the laminated structured grains coarsen abnormally, resulting in an inhomogeneous microstructure. The inhomogeneous microstructure leads to both higher strength and greater ductility. The evolution of grain size distribution of ARB-processed CP Al in during subsequent AR is shown in Fig. 26.
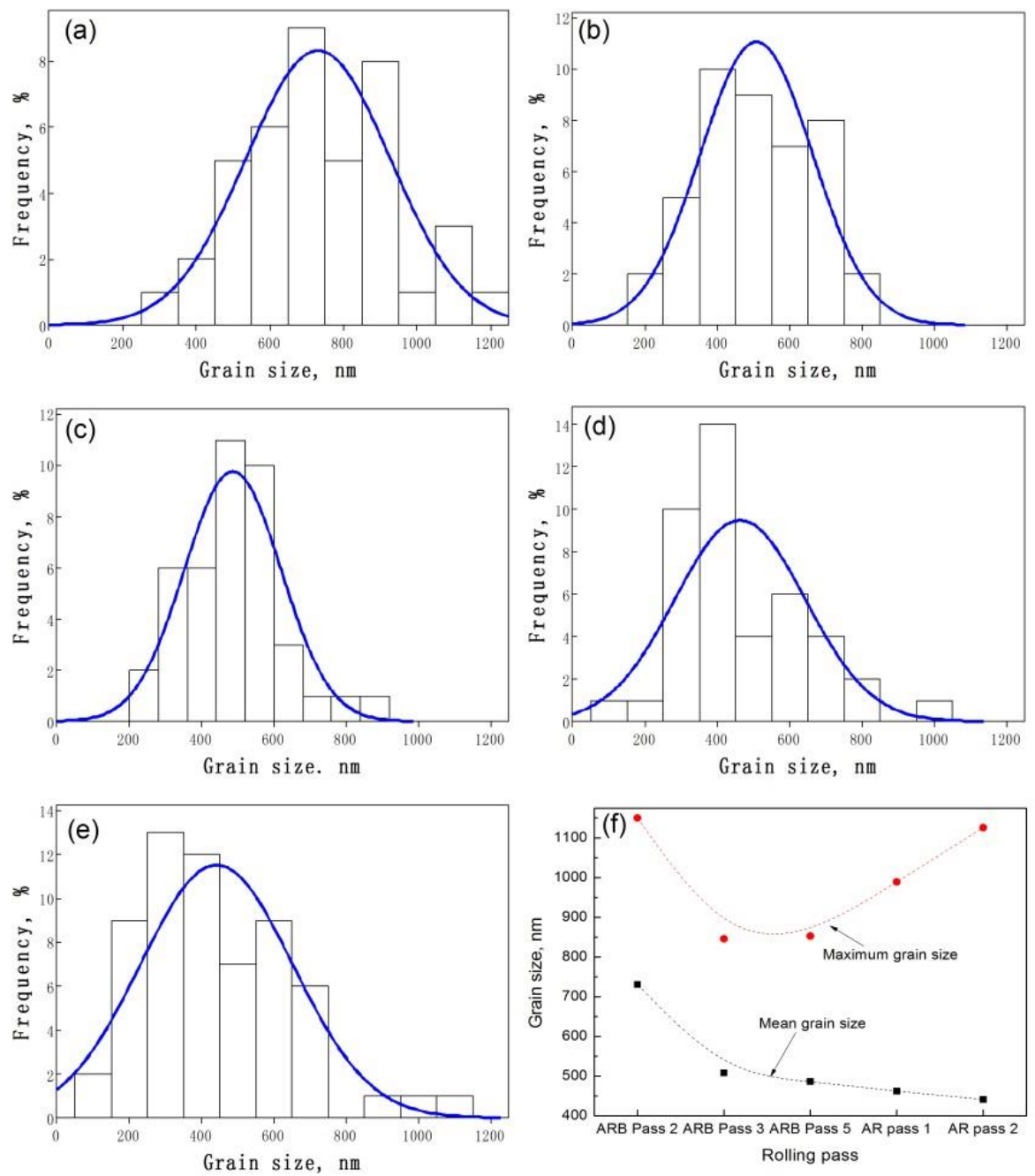

Fig. 26. Grain size distribution after (a) the second ARB pass, (b) the third ARB pass, (c)the fifth ARB pass, (d) the first AR pass, (e) the second AR pass, and (f) the mean and the maximum grain size after different rolling passes. ${ }^{[130]}$

Post-ARB rolling also affects the thermal stability of ARB-processed samples. A 
$200 \mu \mathrm{m}$ thickness sheet was fabricated by 3 ARB passes plus subsequent cold rolling of annealed sheets of $1 \mathrm{~mm}$ thickness of distributed precipitates by Gatti and Bhattacharjee. ${ }^{[131]}$ They found annealing at higher temperature leads to an abnormal layered microstructure with deformed layer sandwiched by recrystallized layers. Homola et al ${ }^{[132]}$ studied the thermal stability of Al-Fe-Mn-Si foils produced using (ARB + cold rolling) through comparison with conventional cold rolled samples. They found that the cold-rolled samples show discontinuous recrystallization, whereas the $(\mathrm{ARB}+$ cold rolled $)$ samples undergo continuous recrystallization.

\section{Summary}

Table 1 summarizes the special rolling techniques and their characteristics respectively.

Table 1. Characteristics of special rolling techniques.

\begin{tabular}{|c|c|}
\hline Technique & Feature \\
\hline $\begin{array}{l}\text { Asymmetric } \\
\text { rolling }\end{array}$ & $\begin{array}{l}\text { Refining grains through additional shear strain and normal strain; } \\
\text { reducing rolling pressure by shear deformation. The technique can } \\
\text { improve both strength and ductility of } \mathrm{Al}, \mathrm{Mg}, \mathrm{Ti}, \mathrm{Cu} \text {, etc. }{ }^{[39-56]}\end{array}$ \\
\hline Cryorolling & $\begin{array}{l}\text { Refining grains through suppressing dynamic recovery during } \\
\text { deformation. The technique can improve the mechanical properties of } \\
\mathrm{Al}, \mathrm{Zr} \text {, Ti, etc. }{ }^{[57-78]}\end{array}$ \\
\hline $\begin{array}{l}\text { Asymmetric } \\
\text { cryorolling }\end{array}$ & $\begin{array}{l}\text { Combining the features of } \mathrm{AR} \text { and cryorolling. The technique can } \\
\text { improve the mechanical properties of } \mathrm{Al} \text {, etc. }{ }^{[79-84]}\end{array}$ \\
\hline Cross-ARB & $\begin{array}{l}\text { Making the microstructure uniform and reducing the anisotropy of } \\
\text { sheets. The technique can improve the mechanical properties of } \\
\text { Al-matrix composite, etc. }{ }^{[90-95]}\end{array}$ \\
\hline Four-layer ARB & $\begin{array}{l}\text { Improving the bonding quality of layers during room temperature } \\
\text { deformation. The technique can improve the mechanical properties of } \\
\text { Al, IF steel, etc. }{ }^{[97-98]}\end{array}$ \\
\hline Skin-pass rolling & $\begin{array}{l}\text { Changing the microstructure at surface of workpiece. Improving the } \\
\text { ductility without reduction of strength. The technique can improve the }\end{array}$ \\
\hline
\end{tabular}


mechanical properties of $\mathrm{Al}$ etc. ${ }^{[110]}$

Changing equiaxed grains into laminate structure or bimodal structure.

ECAP+rolling The technique can improve the mechanical properties of $\mathrm{Cu}, \mathrm{Ti}, \mathrm{Mg}$ etc. [111-122]

HPT + rolling

Making the microstructure of samples uniform. The technique can improve the mechanical properties of $\mathrm{Cu}$ etc. ${ }^{[123-125]}$

$\mathrm{ARB}+$ rolling Improving the bonding strength, ductility and strength of sheets. The technique can improve the mechanical properties of $\mathrm{Al}$ etc. ${ }^{[126-131]}$

The development of SPD techniques has enabled significant improvement in the strength of UFG/NG materials. However, most UFG/NG materials still lack the necessary toughness required in engineering applications although there are many the mechanisms for enhancing ductility of UFG/NG metals. ${ }^{[133]}$ These techniques include:

(i) Narrow grain size distribution. During asymmetric rolling, a shear strain is imposed throughout the sheet thickness, increasing the grain homogeneity across the thickness. During CARB, the grains become more homogeneous owing to reduced anisotropy.

(ii) Deformation at cryogenic temperatures. Both cryorolling and asymmetric cryorolling have been shown to improve the ductility and strength of sheets.

(iii) Gradient structure. SPR processing only results in grain refinement near the surface and results in gradient structure in the sheets. HPT followed by rolling can also result in a gradient structure in the samples.

(iv) Bimodal structure. In samples subjected to ECAP or ARB followed by rolling, the grains evolve into a bimodal structure, improving both the ductility and the strength of the samples. In addition, annealing SPD-processed samples also results in a bimodal structure in some materials.

(v) Precipitation-hardened alloys. Asymmetric cryorolling followed by an ageing treatment can improve the ductility and strength of the sheets. 
(vi) Nanotwinned structure. In UFG Cu samples subjected to HPT followed by rolling and annealing, the occurrence of nanotwins improves the mechanical properties.

There are some other mechanisms which can improve the ductility of UFG/NG materials: such as transformation-induced enhancement of ductility and tailoring of the stacking fault energy by alloying. In the future, these mechanisms may be also incorporated into rolling techniques. In addition, using a combination of different SPD techniques with rolling, the ductility and strength of UFG/NG materials could be improved. The evolution in the microstructure of NG materials subjected to SPD (e. g. HPT) followed by rolling and annealing ${ }^{[134]}$ should also be studied in the future.

\section{References}

[1] A. Lasalmonie, J. L. Strudel, J. Mater. Sci. 1986, 21, 1837.

[2] R. Valiev, Nature Mater. 2004, 3, 511.

[3] X. C. Liu, H. W. Zhang, K. Lu, Science, 2013, 342, 337.

[4] Y. Huang, T. G. Langdon, Mater. Today 2013, 16, 85.

[5] Y. Iwahashi, Z. Horita, M. Nemoto, T. G. Langdon, Acta Mater. 1998, 46, 3317.

[6] R. Z. Valiev, R. K. Islamgaliev, I. V. Alexandrov, Prog. Mater. Sci. 2000, 45, 103.

[7] R. Z. Valiev, T. G. Langdon, Prog. Mater. Sci. 2006, 51, 881.

[8] A. P. Zhilyaev, T. G. Langdon, Prog. Mater. Sci. 2008, 53, 893.

[9] I. J. Beyerlein, L. S. TÓth, Prog. Mater. Sci. 2009, 54, 427.

[10] Y. Estrin, A. Vinogradov, Acta Mater. 2013, 61, 782.

[11] T. G. Langton, Acta Mater. 2013, 61, 7035.

[12] T. Sakai, A. Belyakov, R. Kaibyshev, H. Miura, J. J. Jonas, Prog. Mater. Sci. 2014, 60, 130.

[13] N. Tsuji, Y. Saito, S. H. Lee, Y. Minamino, Adv. Eng. Mater. 2003, 5, 338.

[14] G. Hirt, S. Senge, Procedia Eng. 2014, 81, 18.

[15] H. L. Yu, X. H. Liu, X. M. Zhao, Y. Kusaba, J. Mater. Process. Technol. 2006, 180, 323.

[16] H. L. Yu, X. H. Liu, G. T. Lee, H. D. Park, J. Mater. Process. Technol. 2008, $208,42$.

[17] H. L. Yu, X. H. Liu, G. T. Lee, ISIJ Int. 2007, 47, 996.

[18] A. S. Deshpande, K. S. Murthy, J. Mater. Process. Technol. 1997, 63, 712.

[19] Z. Yuan, H. Xiao, H. Xie, Metall. Mater. Trans. A 2014, 45, 1019.

[20] H. L. Yu, X. H. Liu, H. Y. Bi, L. Q. Chen, J. Mater. Process. Technol. 2009, 209, 455.

[21] H. L. Yu, X. H. Liu, C. S. Li, Y. Kusaba, J. Iron Steel Res. Int. 2006, 13, 31.

[22] H. L. Yu, X. H. Liu, Mater. Manuf. Process. 2009, 24, 570.

[23] H. L. Yu, X. H. Liu, C. S. Li, H. F. Lan, G. D. Wang, J. Mater. Process. Technol. 2009, 209, 2876.

[24] H. L. Yu, K. Tieu, C. Lu, G. Y. Deng, X. H. Liu, Int. J. Adv. Manuf. Technol. 2013, 67, 1161.

[25] E. Ervasti, U. Ståhlberg, J. Mater. Process. Technol. 2000, 101, 312.

[26] H. L. Yu, X. H. Liu, X. W. Li, A. Godbole, Metall. Mater. Trans. A 2014, 45, 1001.

[27] X. H. Liu, Y. Zhi, H. L. Yu, Mater. Manuf. Process. 2010, 25, 161. 
[28] L. Chen, Z. Zeng, Y. Zhao, F. Zhu, X. Liu, Metall. Mater. Trans. A 2014, 45, 1498.

[29] N. S. Barekar, B. K. Dhindaw, Mater. Manuf. Process. 2014, 29, 651.

[30] D. Choudhuri, S. Meher, S. Nag, N. Dendge, J. Y. Hwang, R. Banerjee, Philos. Mag. Lett. 2013, 93, 395.

[31] C. S. Li, H. L. Yu, G. Y. Deng, X. H. Liu, G. D. Wang, J. Iron Steel Res. Int, 2007, 14, 18.

[32] Q. Wang, Z. Jiang, J. Zhao, M. Fang, Tribol. Int. 2013, 67, 174.

[33] E. V. Zaretsky, Mater. Sci. Technol. 2012, 28, 58.

[34] D. J. Wentink, D. Matthews, N. M. Appelman, E. M. Toose, Wear, 2015, 328-329, 167.

[35] Y. Saito, H. Utasunomiya, N. Tsuji, T. Sakai, Acta Mater. 1999, 47, 579.

[36] H. L. Yu, C. Lu, K. Tieu, A. Godbole, L. H. Su, Y. Sun, M. Liu, D. Tang, C. Kong, Sci. Rep. 2013, 3, 2373.

[37] L. H. Su, C. Lu, K. Tieu, G. Y. Deng, X. D. Sun, Mater. Sci. Eng. A 2013, 559, 345.

[38] J. S. Carpenter, T. Nizolek, R. J. McCabe, M. Knezevic, S. J. Zheng, B. P. Eftink, J. E. Scott, S. C. Vogel, T. M. Pollock, N. A. Mara, I. J. Beyerlein, Acta Mater. 2015, 92, 97.

[39] Q. Cui, K. Ohori, Mater. Sci. Technol. 2000, 16, 1095.

[40] Y. H. Ji, J. J. Park, Mater. Sci. Eng. A 2009, 499, 14.

[41] D. L. Tang, X. H. Liu, M. Song, H. L. Yu, Plos One, 2014, 9, e106637.

[42] Q. B. Yu, X. H. Liu, D. L. Tang, Sci. Rep. 2013, 3, 3556.

[43] R. J. Alves de Sousa, F. J. P. Simóes, J. J. Grácio, J. W. Yoon, Int. J. Mater. Form. 2010, 3, 61.

[44] K. H. Kim, D. H. Lee, Acta Mater. 2001, 49, 2583.

[45] J. Sidor, R. H. Petrov, L. A. I. Kestens, Mater. Sci. Eng. A 2010, 528, 413.

[46] J. H. Jiang, Y. Ding, F. Q. Zuo, A. D. Shan, Scr. Mater. 2009, 60, 905.

[47] B. Beausir, S. Biswas, D. I. Kim, L. S. Tóth, S. Suwas, Acta Mater. 2009, 57, 5061.

[48] S. Biswas, D. I. Kim, S. Suwas, Mater. Sci. Eng. A 2012, 550, 19.

[49] H. Watanabe, T. Mukai, K. Ishikawa, J. Mater. Sci. 2004, 39, 1477.

[50] H. Watanabe, T. Mukai, K. Ishikawa, J. Mater. Process. Technol. 2007, 182, 644.

[51] R. Ma, L. Wang, Y. N. Wang, D. Z. Zhou, Mater. Sci. Eng. A 2015, 638, 190.

[52] K. M. Lee, H. C. Lee, J. Mater. Process. Technol. 2010, $210,1574$.

[53] M. H. Cai, S. S. Dhinwal, Q. H. Han, Q. Chao, P. D. Hodgson, Mater. Sci. Eng. A 2013, 583, 205.

[54] D. Orlov, R. Lapovok, L. S. Toth, I. B. Timokhina, P. D. Hodgson, A. Haldar, D. Bhattacharjee, Metall. Mater. Trans. A 2014, 45, 447.

[55] Z. M. Li, L. M. Fu, B. Fu, A. D. Shan, Mater. Sci. Eng. A 2012, 558, 309.

[56] G. Angella, B. Esfandiar Jahromi, M. Vedani, Mater. Sci. Eng. A 2013, 559, 742.

[57] D. Meryer, CIRP Ann. Manuf. Technol. 2012, 61, 543.

[58] V. Subramanya Sarma, J. Wang, W. W. Jian, A. Kauffmann, H. Conrad, J. Freudenberger, Y. T. Zhu, Mater. Sci. Eng. A 2010, 527, 7624.

[59] N. Rangaraju, T. Raghuram, B. V. Krishna, K. P. Rao, P. Venugopal, Mater. Sci. Eng. A 2005, $398,246$.

[60] J. Marnett, M. Weiss, P. D. Hodgson, Mater. Des. 2014, 63, 471.

[61] T. Shanmugasundaram, B. S. Murty, V. Subramanya Sarma, Scr. Mater. 2006, 54, 2013.

[62] Y. B. Lee, D. H. Shin, K. T. Park, W. J. Nam, Scr. Mater. 2004, 51, 355.

[63] D. Singh, P. N. Rao, R. Jayaganthan, Mater. Des. 2013, 50, 646.

[64] S. K. Panigrahi, R. Jayaganthan, Mater. Sci. Eng. A 2008, 492, 300. 
[65] S. K. Panigrahi, R. Jayaganthan, Metall. Mater. Trans. A 2010, 41, 2675.

[66] S. K. Panigrahi, R. Jayaganthan, V. Chawla, Mater. Lett. 2008, 62, 2626.

[67] S. K. Panigrahi, R. Jayaganthan, J. Alloy. Comp. 2009, 470, 285.

[68] S. K. Panigrahi, R. Jayaganthan, Metall. Mater. Trans. A 2011, 42, 3208.

[69] P. Das, R. Jayaganthan, T. Chowdhury, I. V. Singh, Mater. Sci. Eng. A 2011, 528, 7124.

[70] D. C. C. Magalhães, M. F. Hupalo, O. M. Cintho, Mater. Sci. Eng. A 2014, 593, 1.

[71] P. Trivedi, S. Goel, S. Das, R. Jayaganthan, D. Lahiri, P. Roy, Mater. Sci. Eng. C 2015, 46, 309.

[72] Y. D. Shi, M. Li, D. F. Guo, T. Y. Ma, Z. B. Zhang, X. H. Li, G. S. Zhang, X. Y. Zhang, Adv. Eng. Mater. 2014, 16, 167.

[73] G. S. D’yakonov, S. V. Zherebtsov, M. V. Klimova, G. A. Salishchev, Phys. Metal. Metall. 2015, 116, 182.

[74] D. K. Yang, P. D. Hodgson, C. E. Wen, Scr. Mater. 2010, 63, 941.

[75] S. V. Zherebtsov, G. S. Dyakonov, A. A. Salem, V. I. Sokolenko, G. A. Salishchev, S. L. Semiatin, Acta Mater. 2013, 61, 1167.

[76] T. Konkova, S. Mironov, A. Korznikov, S. L. Semiatin, Acta Mater. 2010, 58, 5262.

[77] B. Roy, R. Kumar, J. Das, Mater. Sci. Eng. A 2015, 631, 241.

[78] K. L. Ye, H. Y. Lou, J. L. Lv, Mater. Manuf. Process. 2014, 29, 754.

[79] R. O. Ritchie, Nature Mater. 2011, 10, 817.

[80] U. G. K. Wegst, H. Bai, E. Saiz, A. P. Tomsia, R. O. Ritchie, Nature Mater. 2014, 14, 23.

[81] H. L. Yu, C. Lu, K. Tieu, X. H. Liu, Y. Sun, Q. B. Yu, C. Kong, Sci. Rep. 2012, 2, 772.

[82] H. L. Yu, K. Tieu, C. Lu, X. H. Liu, A. Godbole, C. Kong, Mater. Sci. Eng. A 2013, 568, 212.

[83] H. L. Yu, K. Tieu, C. Lu, Y. S. Lou, X. H. Liu, A. Godbole, C. Kong, Int. J. Damage Mech. 2014, 23, 1077.

[84] H. L. Yu, A. K. Tieu, C. Lu, X. Liu, M. Liu, A. Godbole, C. Kong, Q. H. Qin, Sci. Rep. 2015, $5,9568$.

[85] M. Hockauf, L. W. Meyer, J. Mater. Sci. 2010, 45, 4778.

[86] J. W. Zhang, N. Gao, M. J. Starink, Mater. Sci. Eng. A 2010, 527, 3472.

[87] F. Q. Zuo, J. H. Jiang, A. D. Shan, J. M. Fang, X. Y. Zhang, Trans. Nonfer. Metal. Soc. China, 2008, 18,774 .

[88] H. Pirgazi, A. Akbarzadeh, R. Petrov, L. Kestens, Mater. Sci. Eng. A 2008, 497, 132.

[89] D. Orlov, Y. Beygelzimer, S. Synkov, V. Varyukhin, N. Tsuji, Z. Horita, Mater. Trans. 2009, $50,96$.

[90] M. Alizadeh, Mater. Lett. 2010, 64, 2641.

[91] Y. Kim, S. Kang, D. Shin, Mater. Sci. Forum, 2006, 503-504, 681.

[92] H. Azzeddine, K. Tirsatine, T. Baudin, A. Helbert, F. Brisset, D. Bradai, Mater. Charac. 2014, $97,140$.

[93] M. Ruppert, H. W. Höppel, M. Göken, Mater. Sci. Eng. A 2014, 597, 122.

[94] M. Alizadeh, M. H. Paydar, Mater. Sci. Eng. A 2012, 538, 14.

[95] M. Alizadeh, E. Salahinejad, J. Alloy. Comp. 2015, 620, 180.

[96] H. Li, K. Nagai, F. Yin, Sci. Technol. Adv. Mater. 2008, 9, 023001.

[97] H. L. Yu, C. Lu, K. Tieu, C. Kong, Mater. Manuf. Process. 2014, 29, 448.

[98] R. Jamaati, M. R. Toroghinejad, S. Amirkhanlou, H. Edris, Metall. Mater. Trans. A 2015, DOI, 10. 1007/s11661-015-3001-6. 
[99] K. Lu, Science, 2014, 345, 1455.

[100] T. H. Fang, W. L. Li, N. R. Tao, K. Lu, Science, 2011, 331, 1587.

[101] X. L. Wu, P. Jiang, L. Chen, F. P. Yuan, Y. T. Zhu, Prol. Natl. Acad. Sci. U. S. A, 2014, 111, 7197.

[102] Y. Wei, Y. Li, L. Zhu, Y. Liu, X. Lei, G. Wang, Y. Wu, Z. Mi, J. Liu, H. Wang, H. Gao, Nature Commun. 2014, 5, 3580.

[103] H. Yang, E. J. Lavernia, J. M. Schoenung, Philos. Mag. Lett. 2015, 95, 177.

[104] H. Kijima, J. Mater. Process. Technol. 2015, 216, 1.

[105] H. Kijima, J. Mater. Process. Technol. 2014, 214, 1111.

[106] H. Kijima, J. Mater. Process. Technol. 2013, 213, 1764.

[107] H. Kijima, N. Bay, Int. J. Mach. Tool. Manuf. 2008, 48, 1308.

[108] H. Kijima, N. Bay, Int. J. Mach. Tool. Manuf. 2008, 48, 1313.

[109] A. M. Giarola, P. H. R. Pereira, P. A. Stemler, A. E. M. Pertence, H. B. Campos, M. T. P. Aguilar, P. R. Cetlin, J. Mater. Process. Technol. 2015, 216, 234.

[110] H. L. Yu, C. Lu, K. Tieu, H. J. Li, A. Godbole, X. Liu, Q. Zhu, C. Kong, Novel fabrication of gradient aluminium sheets via skin-pass rolling. Under reviewing.

[111] S. S. Hazra, A. A. Gazder, A. Carman, E. V. Pereloma, Metall. Mater. Trans. A 2011, 42, 1334.

[112] N. D. Stepanov, A. V. Kuznetsov, G. A. Salishchev, G. I. Raab, R. Z. Valiev, Mater. Sci. Eng. A 2012, 554, 105.

[113] S. R. Bahadori, K. Dehghani, Metall. Mater. Trans. A 2015, 46, 2796.

[114] S. Ranjbar Bahadori, K. Dehghani, F. Bakhashandeh, Mater. Sci. Eng. A 2013, 588, 260.

[115] S. Ranjbar Bahadori, K. Dehghani, F. Bakhashandeh, Mater. Sci. Eng. A 2013, 583, 36.

[116] K. T. Park, H. J. Lee, C. S. Lee, D. H. Skin, Mater. Sci. Eng. A 2005, 393, 118.

[117] K. T. Park, H. J. Lee, C. S. Lee, W. J. Nam, D. H. Shin, Scr. Mater. 2004, 51, 479.

[118] G. F. Lima, M. R. M. Triques, C. S. Kiminami, W. J. Botta, Jr. A. M. Jorge, J. Alloy. Comp. 2014, 586, 5405.

[119] Y. C. Yuan, A. B. Ma, X. F. Gou, J. H. Jiang, F. M. Lu, D. Song, Y. T. Zhu, Mater. Sci. Eng. A 2015, 630, 45.

[120] S. Biswas, D. S. Singh, B. Beausir, L. S. Toth, S. Suwas, Metall. Mater. Trans. A 2015, 46, 2598.

[121] V. V. Stolyarov, L. Zeipper, B. Mingler, M. Zehetbauer, Mater. Sci. Eng. A 2008, 476, 98.

[122] K. Hajizadeh, B. Eghbali, Metal. Mater. Int. 2014, 20, 343.

[123] O. Renk, A. Hohenwarter, S. Wurster, R. Pippan, Acta Mater. 2014, 77, 401.

[124] J. M. Tao, G. M. Chen, W. W. Jian, J. Wang, Y. T. Zhu, X. K. Zhu, T. G. Langdon, Mater. Sci. Eng. A 2015, 628, 207.

[125] X. L. Ma, C. X. Huang, W. Z. Xu, H. Zhou, X. L. Wu, Y. T. Zhu, Scr. Mater. 2015, 103, 57.

[126] H. L. Yu, K. Tieu, C. Lu, A. Godbole, Metall. Mater. Trans. A 2014, 45, 4038.

[127] M. Ruppert, H. W. Höppel, M. Göken, Mater. Sci. Eng. A 2014, 597, 122.

[128] H. L. Yu, C. Lu, K. Tieu, A. Godbole, Y. Sun, M. Liu, L. H. Su, D. L. Tang, C. Kong, Sci. Rep. 2013, 3, 2373.

[129] X. Huang, N. Kamikawa, N. Hansen, J. Mater. Sci. 2008, 43, 7397.

[130] H. L. Yu, K. Tieu, S. Hadi, C. Lu, A. Godbole, C. Kong, Metall. Mater. Trans. A 2015, 46, 869. 
[131] J. R. Gatti, P. P. Bhattacharjee, IOP Conf. Series, Mater. Sci. Eng. 2015, 82, 012045.

[132] P. Homola, M. Slamova, P. Slama, M. Cieslar, Mater. Sci. Forum 2008, 584-586, 905.

[133] I. A. Ocid'Ko, T. G. Langdon, Review. Adv. Mater. Sci. 2012, 30, 103.

[134] H. L. Yu, K. Tieu, C. Lu, C. Kong. Philos. Mag. Lett. 2014, 94, 732. 